\title{
Hospital Infant Formula Discharge Packages: A Blessing Or A Curse?
}

\author{
Fang Guo \\ China
}

M.A. Economics, University of Virginia, 2016

B.A. Economics, Beijing University, 2011

A Dissertation presented to the Graduate Faculty

of the University of Virginia in Candidacy for the Degree of Doctor of Philosphy

Department of Economics

University of Virginia

May, 2017 


\begin{abstract}
This project focuses on the marketing strategy and pricing policy of infant formula manufacturers, consumer response to product lock-ins, and market with high switching costs. Formula companies employ a classic "bargain-then-rip-off" strategy to reel in customers then exploit them. Free gifts in hospital discharge packages are used to tempt mothers who could breastfeed, followed by oppressive price once customers are locked in. I develop a dynamic structural model to characterize the use of marketing and pricing strategies and consumer demand. A finite-horizon hyperbolic discounting model is utilized to account for possible time inconsistency in consumer preferences. For the particular population of US mothers in their first postpartum year, the present bias and the standard discount factors are estimated to be 0.20 and 0.93 respectively - consumers anticipate but underestimate the lock-in effect, reinforcing the "bargain-then-rip-off" strategy.

Formula companies' "bargain-then-rip-off" strategy proves to be a winning one. I find that formula price is $3.6 \%$ higher than the price that a monopolist would charge in a counterfactual world where all hospitals ban infant formula free samples in discharge bags. I also find that if all hospitals go bag free, breastfeeding ratio will increase by approximately $2.0 \%$ each month, each mother will save on average ten dollars from the decrease in infant formula consumption, fifteen dollars from the decrease in infant formula price, and receive higher payoff from child health improvement due to longer breastfeeding duration through the first postpartum year. As a result, consumer welfare will increase by $38.9 \%$ and the formula firm's profit will decrease by $3.2 \%$.

JEL Classifications: D12, D22, L12, L66, M31
\end{abstract}

KEYWORDS: state dependence, time-inconsistent preferences, free samples 


\section{Acknowledgements}

This thesis would not be completed without the generous help of many people. I am indebted to my advisors, Simon Anderson, Federico Ciliberto, Karim Chalak, and Natasha Zhang Foutz for their guidance, support and patience. They have always directed me in the path to higher accomplishment during the last six years. I am grateful for the support of several other faculty members, especially Steve Stern, for all his advice, expertise, and experience which are extremely helpful for my research. I would also like to thank Gaurab Aryal, Leora Friedberg, Kieron Meagher, and Denis Nekipelov for all the enlightening conversations. I benefited so much from their suggestions on both research and writing.

Participants at UVA IO group meetings and Steve Stern's reading group have contributed immensely to my research. They gave me a lot of wonderful comments and ideas. Special thanks to Mattew Shi, Siying Liu, Zhou Zhang, Dina Guo, and Charles Murry. I am very pleased that I have spent the last six years with my fellow graduate students. They made my life and work at UVA an extraordinary loving experience.

Much of the research in this dissertation was done while receiving financial support from the Bankard fund for Political Economy, Steer family travel fund, and Radulovacky fund. I am also grateful to University of Virginia Library for providing access to important data sets. I acknowledge Kilts Marketing Data Center for providing access to AC Nielsen Retailer Scanner Data.

Lastly, I want to thank my parents, Binfang and Kejun, for supporting me without question and taking care of my boy Owen. I also would like to thank my husband and best friend, Albert, for fighting side by side with me. 


\section{Contents}

\begin{tabular}{lll}
\hline & Introduction & 1
\end{tabular}

$\begin{array}{lll}2 & \text { Literature Review } & 7\end{array}$

2.1 Theoretical Models of Switching Cost . . . . . . . . . . . . . . . . . . 7

2.2 Empirical Models of Switching Cost . . . . . . . . . . . . . . . . . . . 9

2.3 Identification of Structural State Dependence . . . . . . . . . . . . . 10

2.4 Empirical Models of Present-Biased Preferences . . . . . . . . . . . . 13

\begin{tabular}{lll}
\hline 3 & Institutional Background & 16
\end{tabular}

3.1 Infant Formula versus Breastfeeding . . . . . . . . . . . . . . . . 16

3.2 Free Samples and the National Campaign. . . . . . . . . . . . . . . . 19

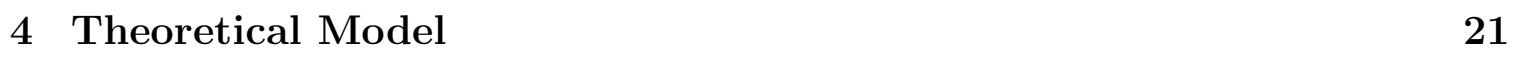

4.1 The Model . . . . . . . . . . . . . . . . . . . . . . . . . . . . . . . . . 21

4.2 Low Switching Cost . . . . . . . . . . . . . . . . . . . . . . . . . 23

4.3 High Switching Cost . . . . . . . . . . . . . . . . . . . . . . . . . . . 29

$\begin{array}{lll}5 & \text { Data and Descriptive Analysis } & 31\end{array}$

5.1 Infant Feeding Practice Studies II (IFPS) . . . . . . . . . . . . . . . 31

5.2 Summary Statistics . . . . . . . . . . . . . . . . . . . . . . . . . . . . . . . . . . . . . . 33

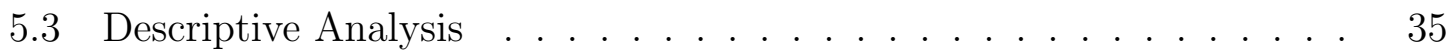

$\begin{array}{lll}6 & \text { Reduced Form Results } & 37\end{array}$

\begin{tabular}{lll}
\hline 7 & Empirical Model & 41
\end{tabular}

7.1 Consumers . . . . . . . . . . . . . . . . . . . . . . . . . . . . . 41

7.2 Manufacturer . . . . . . . . . . . . . . . . . . 50

$\begin{array}{lll}8 & \text { Estimation Strategy } & 57\end{array}$

8.1 Maximum Likelihood Estimation . . . . . . . . . . . . . . . . . . 57

8.2 Identification . . . . . . . . . . . . . . . . . . . 60 
$\begin{array}{lll}9 & \text { Estimation Results } & 62\end{array}$

9.1 Demand Side . . . . . . . . . . . . . . . . . . . . . . . . . 62

9.2 Supply Side . . . . . . . . . . . . . . . . . . . . . . 67

$\begin{array}{ll}10 \text { Counterfactual Analysis } & 69\end{array}$

10.1 All Hospitals "Ban the Bags" . . . . . . . . . . . . . . . . . . . . . . 70

10.2 Without State Dependence . . . . . . . . . . . . . . . . . . 71

\begin{tabular}{ll}
\hline 11 Conclusion & 73
\end{tabular}

$\begin{array}{ll}12 \text { Appendix } & 75\end{array}$

12.1 Figures . . . . . . . . . . . . . . . . . . . . . . . 75

12.2 Tables . . . . . . . . . . . . . . . . . . . . . . . . . . . 88 


\section{Chapter 1}

\section{Introduction}

Since 1981, the World Health Organization has promoted breastfeeding which is recognized as the optimal nutrition for infants. In the U.S., however, breastfeeding ratio is as low as $70 \%$ in early postpartum period, much lower than that in other developed countries. 1 Infant formula products, the major substitutes for breast milk, prevail in both the private pay and the government subsidized markets with the annual sales of the private market reaching over 3.5 billion in 2011. The government subsidized Special Supplemental Nutrition Program for Women, Infants, and Children (WIC) provides free infant formula as nutrition supplements every year for over 2 million infants from low-income households, accounting for more than $50 \%$ of all infants. The International Code of Marketing of Breast-Milk Substitutes, which is not legally enforceable, bans all promotion of infant formula in order to encourage breastfeeding. Governments can adopt all or part of the Code in their legislative system and implement it as law or regulation. Surprisingly, the U.S. has not adopted any entry of the Code and has no legislation on infant formula marketing. As a result, nearly $70 \%$ of

\footnotetext{
${ }^{1}$ Australia (92\%), New Zealand (88\%), Germany (90\%), Norway (99\%)
} 
large hospitals dispense free infant formula samples and over 50 million dollars are spent annually on TV, print, and radio advertisements.

For more than 40 years, formula manufacturers have supplied US hospitals with free formula and newborn discharge pack gifts (most of which contain either formula samples or coupons for formula) for distribution to new mothers. These free discharge packs are an efficient and effective marketing method by which formula manufacturers get new mothers to try their products. Formula companies then adopt a "bargainthen-rip-off" strategy to exploit loyal customers by charging a high price. Brand-name infant formula is always 3 to 4 times as expensive as generic formula. This is due to strong inertia in feeding practice, indicating that once an infant is formula fed (breastfed), she can hardly switch to breast milk (infant formula). When consumers are state dependent, firms face dynamic pricing and marketing incentives, and tend to invest early to lock in new consumers and exploit loyal customers. Since breast milk supply irreversibly discontinues once mothers stop breastfeeding for a period of time, there is great incentive for formula manufacturers to lock in new customers at an early stage. Once customers are locked in, the market size of infant formula sustains. Only then infant formula companies can exploit loyal customers who cannot "vote with their feet".

The "bargain-then-rip-off" strategy is reinforced when consumer preferences are time-inconsistent and present-biased. Although mothers are aware of the lock-in effect, they underestimate the long-term expenditure of formula feeding. They also neglect the long-term benefits of breastfeeding on health improvement because of their short-term impatience. Thus, the courtesy of infant formula free samples disguises the trap to high expenditures. The costly effort to breastfeed outweighs the longterm benefits of breastfeeding. If each consumer puts higher weight on short-term 
cost-saving than long-term expenditure, then formula manufacturers have further incentives to send out free samples and tempt mothers into formula feeding. If mothers breastfeed, they need to exercise costly self control to resist the temptation. Hence, the short-term cost of breastfeeding is magnified, the long-term benefit of breastfeeding and long-term expenditure of formula feeding are belittled. As a result, it is more likely that mothers stop breastfeeding and switch to formula feeding.

Therefore, it has a profound effect on the promotion of breastfeeding to ban free bags of infant formula distributed to new mothers. I develop a structural model characterizing consumer decision on breastfeeding and demand for infant formula, and a formula company's dynamic incentives on pricing. My research quantitatively examines the effect of banning infant formula free packs, as advocated by the International Code, on the promotion of breastfeeding.

To measure the effect of banning infant formula free bags, I build a structural model to capture the dynamic effects of state dependence on both consumers and firms. To characterize consumer problem, I use a finite horizon binary choice model incorporating mothers' previous feeding choice as a covariate. Free infant formula gifts affect mothers' choices only when they breastfeed in the previous period. In my sample, consumers are active for up to one year. In each month of the first postpartum year, mothers make decisions on whether to stop breastfeeding and start formula feeding. Formula feeding is an absorbing state and once mothers stop breastfeeding, they can no longer switch back to breastfeeding. Consumers are forward looking and are aware of the dynamic effect of state dependence on their future consumption. At the terminal age of the dynamic problem, breastfeeding duration affects the continuation value reflecting children's and mothers' future health and welfare.

In my study, two key problems need to be carefully addressed. First, consumer 
state dependence needs to be carefully distinguished from other reasons which can also lead to consumer inertia. If inertia is due to loyalty, then firms can manipulate the evolution of consumer preferences and face dynamic pricing and advertising incentives. In contrast, if inertia is due to other reasons such as unobserved heterogeneity or taste shocks, there are no pricing or advertising dynamics and it will lead to quantitatively different equilibrium outcomes.

To solve the problem, I use individual decision on breastfeeding jointly with preference information collected by Infant Feeding Practice Study data. The study sends out questionnaires to new mothers almost each month in the first postpartum year asking questions about the feeding practice as well as their preferences over infant formula compared to breastfeeding. To separate consumer state dependence from preference heterogeneity, I control for fixed effects of consumer persistent preferences using the information on breastfeeding preferences collected by the survey data. Once controlling for consumer persistent preferences in the model, state dependence can be identified from the persistence of feeding practice.

The second key problem in my study is that inter-temporal preferences are important to understand the tradeoffs faced by consumers. When mothers are exposed to free gifts of infant formula in hospitals, they are tempted to use infant formula to avoid the cost of breastfeeding. If mothers weigh more the short-term cost saving of infant formula in contrast to the long-term expenditure, they will be more easily seduced to feed their babies by infant formula.

To account for possible time inconsistency in consumer preferences described in the second problem, I use a quasi-hyperbolic discounting model to capture the tendency of decision makers to seize short-term rewards at the expense of long-term preferences. Specifically, I estimate the $(\beta, \delta)$ preferences model nesting the standard exponential 
discounting model. The short-term discount factor $\beta$ is estimated to be 0.20 and the long term discount parameter is 0.93 in the present-bias model. The discount factor in the time-consistent model is estimated to be 0.39. The Likelihood Ratio test prefers the present-bias model at 99\% confidence level, indicating that mothers are forward looking and are short-term impatient.

The demand estimation suggests that a stable family, higher education and more experience with breastfeeding can enhance mothers' acknowledgement of the benefits of breastfeeding. Therefore, breastfeeding educational material, adequate assistance and supports are essential in promoting breastfeeding among mothers, especially new mothers who always find it most difficult to start breastfeeding; once they learn how to latch on, how to deal with engorgement, and how to adapt to the body change, they will find breastfeeding not as difficult as it is at the beginning. Hence, more resources should be invested in assisting new mothers to learn and get used to breastfeeding. The government subsidized program WIC is successful in lowering breastfeeding cost and providing breastfeeding aids. However, the program also provides free designated brand-name infant formula to mothers and infants from poor families. Considering the price reduction effect of the program, the net effect of WIC participation on the promotion of breastfeeding is not palatable.

I further develop a simple supply side where a monopolist sets a steady state price. I assume the marginal cost of infant formula free packages is close to zero and marketing intensity is determined by state policy and market environment. The monopolist makes dynamic pricing decisions while taking into account the dynamic behavior of consumers. I estimate the marginal cost of production that rationalizes the pricing strategy and breastfeeding decisions under different discounting assumptions. In the counterfactual analysis, I assume that all hospitals ban the bags and simulate the new 
equilibrium price and breastfeeding ratio. The counterfactual equilibrium price is approximately 1.5 dollars lower than the price in the real world, leading to an increase of around $2.0 \%$ in breastfeeding ratio through the first postpartum year. Each consumer will on average save ten dollars from the decrease in the use of infant formula and fifteen dollars from the decrease in the formula price each year. Mothers will further gain welfare increase from longer breastfeeding duration, resulting in a total $38.86 \%$ increase in consumer welfare and $3.20 \%$ decrease in firm profit. Consumers gain a higher percentage of welfare increase than firm profit loss. Social welfare will increase if commercial discharge bags with free infant formula samples are banned. In another counterfactual analysis, I simulate the equilibrium price and breastfeeding ratio in a world where state dependence in breast milk is absent. The analysis illustrates that breastfeeding ratio dramatically decreases in the counterfactual scenario due to the lack of state dependence and the increase in price.

In the next chapter, I will review the literature relevant to my research. In the third chapter, I will introduce the institutional background of infant formula and breastfeeding. In chapter four, I will build a theoretical model with state dependence and discuss the possibility that state dependence has no effect on breastfeeding ratio. In the next two chapters, I will describe the data I use and show preliminary analysis results. Then I will build the structural model in the seventh chapter and discuss the estimation strategy and estimation results in the next two chapters. At last I will conduct counterfactual analysis and conclude. 


\section{Chapter 2}

\section{Literature Review}

This research is closely related to four sets of literature: theoretical models of switching cost; empirical models of switching cost; identification of structural state dependence; and lastly, empirical models of present-biased preferences. In this section, I discuss the most relevant papers.

\subsection{Theoretical Models of Switching Cost}

My work is related to research on the impact of switching costs on price competition dating back to Klemperer (1987). A series of two-period or infinite-horizon models have been developed and shown that switching costs lead to higher equilibrium prices 1 For example, Farrell and Shapiro (1998) consider an infinite-horizon model where a new cohort of consumers enter the market in each period. They assume there is no consumer heterogeneity beyond switching cost and conclude that switching costs increase market price. However, most of these papers assume away switching in

\footnotetext{
${ }^{1}$ Beggs and Klemperer(1992), Farrell and Shapiro (1998), To (1995) and Padilla (1995). For a detailed survey see Farrell and Klemperer (2007).
} 
equilibrium (either by assumption, or because switching costs were assumed very large).

Noting that the assumption of infinite switching costs upward biased equilibrium price, researchers start to examine the effect when assuming switching cost is small. There is a string of theoretical papers showing that switching costs can be pro-competitive as they lead to lower prices under certain circumstances. They relax assumptions and generalize the model to where switching behavior may occur in equilibrium. (Doganoglu (2010), Cabral (2012), Fabra and Garcia (2012), Biglaiser et al. (2013), and Pearcy (2014), etc.) They also derive conditions under which switching cost can be pro-competitive.

For example, Cabral (2016) builds a model of two firms supplying differentiated products in an infinite-period game. Sellers can price discriminate locked-in and not-locked-in buyers. He derives conditions under which switching costs decrease or increase equilibrium prices. Rhodes (2014) looks at an infinite-period model with overlapping generations of two-period lived forward looking consumers. He assumes that firms cannot discriminate between consumers. He finds a "general presumption that in the long-run, switching costs make markets more competitive." Pearcy (2014) further generalizes the model to incorporate $n$ firms in the game with overlapping generations of forward looking consumers, as well as allowing for heterogeneous preferences and heterogeneous switching cost. He shows that the larger the number of firms, the more competitive the effect of switching cost is. Shin and Sudhir (2009) replicate the U-shaped relationship between switching costs and equilibrium average prices shown in Dube, Hitsch and Rossi (2009) in a two period Hotelling model with changing preferences. They conclude that the presence of preference heterogeneity (product differentiation) and changing preferences over time are critical for the U- 
shaped relationship between switching cost and market competitiveness.

\subsection{Empirical Models of Switching Cost}

The empirical studies on switching cost is much less abundant relative to theoretical literature. The limited literature features extensive use of static models and statistical inferences. These papers tend to solve the question by investigating market outcomes without understanding individual's decision process. Shy (2002) shows how switching cost can be inferred from observed brands' prices and market shares in a cellular phone market and a market for bank deposits based on assumptions of myopic consumers and homogeneous products. Shi (2006) and Viard (2007) study the case of "wireless number portability" in the cellular phone industry and conclude that reduced switching costs increase competition which implies that gains from higher prices to "locked-in" consumers exceeded the incentives to capture new consumers.

A class of research has tried to distinguish alternative possible explanations for state dependence. These papers mostly emphasize the dynamic aspect brought up by the underlying sources of switching cost. Keane (1996), Ackerberg (2003), Crawford and Shum (2005), Erdem et al. (2005) build models to emphasize the importance of learning in generating consumer persistence in choices. They believe that imperfect information and uncertainty about product quality generate dependence in product choice. Another class of literature focused on the durability of goods and "hold to buy" may result in consecutive possession of the same product. For instance, Carranza (2006), Gordon (2006), Gowrisankaran and Rysman (2007) and Melnikov (2013) build dynamic models to characterize the consumer demand when products are durable and gradually establish a standard estimation strategy for the dynamic model. 
Other dynamic models treat state dependence as extra utility earned from repeated purchase, deriving from brand loyalty, transaction costs, psychological reasons, habit persistence, learning about quality through trial, inventory behavior, variety seeking behavior, switching costs, and so on.

Some papers further estimate state dependence and investigate how switching cost affect pricing decision in the supply side in a counterfactual analysis. Dube et al. (2009) build on a large empirical literature that has documented the existence of brand loyalty or state-dependence in consumer choice and conclude that a small level of switching costs decreases steady state price. Although they assume consumers are myopic and do not consider the impact of current purchase decisions on future utility, they model a monopolist maximizing discounted total utilities and solve a steady state in a stationary environment. Shcherbakov (2013) studies the television industry and build an infinite horizon dynamic model of forward-looking consumers with switching cost. Following Gowrisankaran and Rysman (2007), the state of the market is boiled down to an exclusive value evolving according to an $\mathrm{AR}(1)$ process estimated separately. A simple supply side framework is then estimated as well as the effects of switching costs on the equilibrium policy choice under hypothetical monopoly and duopoly market structures.

\subsection{Identification of Structural State Dependence}

My work is also related to literature on identification of structural state dependence. A salient feature of consumer purchases is that consumers exhibit persistence in their product choices. According to Heckman (1981), persistence in product choices may arise from three sources: (i) permanent unobserved heterogeneity in preferences, (ii) 
serial correlation in taste shocks, or (iii) true or structural state dependence. The first two sources lead to "spurious state dependence" that arises out of failure to control for unobserved heterogeneity. The third source involves a causal effect of past choices on current choice and "structural state dependence". The distinction between these sources is important in firm's optimal policies.

Dating back to Heckman (1981), the identification of structural state dependence from "spurious state dependence" calls for extensive research. Many marketing papers as well as econometric papers have attempted to control for individual heterogeneity and estimate non-linear dynamic panel data models with lagged dependent variables.

Among the econometric papers, individual unobserved heterogeneity is identified as random effects or fixed effects subject to various conditions. Arellano and Carrasco (2003) and Wooldridge (2005) adopt random effects identification strategy by assuming a specific distribution relationship between predetermined explanatory variables, lagged dependent variable, unobserved persistent heterogeneity random effect, and unobservable individual-specific time-varying component. However, this approach relies on correct specification of the distribution and neglects the correlation between unobserved heterogeneity and explanatory variables. Another class of literature uses semiparametric identification to distinguish between fixed effect and "structural state dependence" in binary choice models. Honore and Kyriazidou (2000) propose an identification strategy to accommodate individual fixed effect and lagged dependent variable. They consider trends in the dependent variable $\{1,0,1,1\}$ and $\{0,1,0,0\}$ when only the exogenous variables between the second and third observations are constant. Then the fixed effect is differenced out between the two trends, leaving state dependence identified by the switch between the second and third ob- 
servations. $2^{2}$ Honore and Lewbel (2002) and Paulson (2014) employ an explanatory variable with unbounded support to help identify the binary choice model. The unbounded support assumption ensures that the condition choice probability is close to zero or one and can thus help identify state dependence. Honore and Tamer (2006) and Chernozhukov et al. (2010) investigate the possibility of bounding the range of the marginal effect of interest instead of point estimation. However, these identification strategies may enforce overly strong assumptions in empirical applications.

The identification in marketing papers is relatively less rigorous and mainly relies on the combination of functional form assumptions about the nature of heterogeneity and choice set variation across time. In Dube et al. (2009), switching costs are identified by the switching behavior of consumers' choices in response to price changes, They make bare distributional assumptions related to the distribution of error terms. This flexibility avoids incorrect estimate of structural state dependence caused by misspecification of the error distribution. Papers using market-level data identify "structural state dependence" by assuming that the sum of the dependent variable for each individual is a "sufficient statistic" for the individual fixed effect. They argue that if the switching cost is zero, any change in the product attributes and socioeconomic variables should instantly affect the market share. In contrast, a positive switching cost delays the adjustment of the market share. Therefore, the past product attributes and socioeconomic variables can be used to construct moment conditions that identify the switching costs. $\mathrm{I}^{3}$ Other research takes advantage of exogenous market changes or choice set variation which generate or eliminate switching cost to identify state dependence. Nosal (2012) uses the strictly monotonic relationship between switching

\footnotetext{
${ }^{2}$ Chintagunta et al. (2001) provides an empirical application of the estimator proposed in Honore and Kyriazidou (2000).

${ }^{3}$ See Ho (2014).
} 
cost and the market share of the newly entered product. Sudhir and Yang (2014) exploit the choice-consumption mismatch in rental car business as exclusion restrictions to disentangle state dependence and heterogeneity since consumption based on free upgrades only affects state dependence but not preference heterogeneity. Horsky, et.al. (2012) use individual consumer brand choice panel data jointly with preference information from the same individuals to disentangle preference heterogeneity and state dependence.

\subsection{Empirical Models of Present-Biased Preferences}

Experiments and Field studies have found that short-term discount rates are higher than long-term discount rates. $4^{4}$ Hyperbolic discounting functions can capture this property. This discounting structure embraces the conflict between today's preferences and the preferences that will be held in the future, namely "preference reversal". For example, from today's perspective, the discount rate between two far-off periods, $j$ and $j+1$, is the long-term low discount rate, while from the time $j$ perspective, the discount rate between $j$ and $j+1$ is the short-term high discount rate. As a result, the optimal policy derived at period $j$ for period $j^{\prime}>j$ is different from the optimal policy when the agent arrives at period $j^{\prime}$.

Another associated problem of self-control can also lead to "preference reversal". The main difference between time inconsistent models and self control preferences models is that self control preferences do not imply dynamic inconsistency. They allow agents to self control against immediate rewards temptation. Self-control preferences assume that agents maximize a utility function that is a "compromise" between the

\footnotetext{
${ }^{4}$ Ainslie (1992), Loewenstein and Elster (1992)
} 
standard utility (or "commitment" utility) and a "temptation" utility.5

A small number of empirical papers have estimated the hyperbolic discounting preferences. For example, Laibson et al. (2007) build a structural buffer stock consumption model including many realistic features such as stochastic labor income, liquidity constraints, child and adult dependents, liquid and illiquid assets, revolving credit, and retirement. They use the method of simulated moments (MSM) to estimate time preferences - both short-run and long-run discount rates. The model is identified from matching the model's predictions of retirement wealth accumulation, credit card borrowing, and consumption income comovement with those observed in the data. Their benchmark estimates imply a $40 \%$ short-term annualized discount rate and a $4.3 \%$ long-term annualized discount rate. Paserman (2008) estimates the structural parameters of a job search model with hyperbolic discounting and endogenous search effort, using data on duration of unemployment spells and accepted wages from the National Longitudinal Survey of Youth (NLSY). Under parametric assumptions, identification of the hyperbolic discounting parameters comes from the variation in the relative magnitude of unemployment duration and accepted wages. He rejects the exponential discounting model and finds that low and median wage workers have a higher degree of short-run impatience $(0.40-0.48$ of short-run discount factor) than high wage workers (0.89 of short-run discount factor). Fang and Silverman (2009) empirically implement a dynamic structural model of labor supply and welfare program participation for never-married mothers with potentially time inconsistent preferences. Using panel data on the choices of single women with children from the NLSY 1979, they provide estimates of the degree of time inconsistency and of its influence on the welfare take-up decision. For the particular population of single

\footnotetext{
${ }^{5}$ Kumru and Thanopoulos (2011)
} 
mothers with dependent children, they estimate the present-bias and the standard discount factors to be 0.338 and 0.88 , respectively, implying a one-year-ahead discount rate of $238 \%$. Fang and Wang (2015) extend the semi-parametric estimation method for dynamic discrete choice models using Hotz and Miller's conditional choice probability approach to the setting where individuals may have hyperbolic discounting time preferences and may be naive about their time inconsistency. They illustrate the proposed identification and estimation method with an empirical application of adult women's decisions to undertake mammography to evaluate the importance of present-bias and naivety in the underutilization of this preventive health care. Their results show the present-bias factor ranges from 0.508 to 0.791 and the naivety parameter is bigger than present-bias parameter and close to one, indicating that consumers are nearly completely naive. 


\section{Chapter 3}

\section{Institutional Background}

\subsection{Infant Formula versus Breastfeeding}

Breastfeeding has been recognized as the optimal nutrition for infants. It is estimated that more than a million deaths of babies could be prevented globally per year through more widespread breastfeeding. Breastfeeding decreases the risk of respiratory tract infections and diarrhea. Other benefits include lower risks of asthma, food allergies, celiac disease, type 1 diabetes, and leukemia. Breastfeeding may also improve cognitive development and decrease the risk of obesity in adulthood. Benefits of breastfeeding for the mother include less blood loss following delivery, better uterus shrinkage, weight loss, and less postpartum depression. It also increases the time before menstruation and fertility returns, known as lactational amenorrhea. Long term benefits may include a decreased risk of breast cancer, cardiovascular disease, and rheumatoid arthritis. Breastfeeding is less expensive for the family than infant formula. Health organizations, including the World Health Organization (WHO), recommend feeding for six months only through breastfeeding. 
In the U.S., slightly above $70 \%$ of newborn infants are breastfed in their early postpartum period. However, the ratio drops sharply to $40 \%$ among 6-month-old infants and $20 \%$ among one-year-old infants.1 The International Code of Marketing of Breastmilk Substitutes was developed as a global public health strategy and recommends restrictions on the marketing of breastmilk substitutes, such as infant formula, to ensure that mothers are not discouraged from breastfeeding and that substitutes are used safely if needed. An international boycott campaign has targeted at the Swiss giant Nestle's marketing practices since the development of the Code. The International Code is not legally enforceable on its own. Companies are only subject to legal sanctions for failing to abide by the Code where it has been incorporated into the legislature of a nation state. As of March 2016, 135 out of 194 countries had some form of legal measure in place covering some provisions of the Code. However, the U.S. has taken no legal measures in regards to it.2

To promote breastfeeding, the Special Supplemental Nutrition Program for Women, Infants and Children (WIC) offers guidance and support to mothers with infants. The eligibility requirement is a family income below $185 \%$ of the U.S. Poverty Income Guidelines. Currently, WIC serves $53 \%$ of all infants born in the United States. However, the program also provides formula voucher to low income mothers, accounting for $57-68 \%$ of all infant formula sold in 2004-2006. ${ }^{3}$ The state agency selects a single source (such as a single infant formula manufacturer offering the lowest price), as determined by the submission of sealed bids, for a product for which bids are

\footnotetext{
${ }^{1}$ Centers for Disease Control and Prevention. Breastfeeding among U.S. Children Born 20012011, CDC National Immunization Survey. Available at http://www.cdc.gov/breastfeeding/ data/nis_data/ accessed August 1, 2016

${ }^{2}$ Marketing of breast-milk substitutes: national implementation of the International Code, World Health Organization. Status Report 2016

${ }^{3}$ Oliveira et al. Rising infant formula costs to the WIC program: Recent trends in rebates and wholesale prices, Economic Research Report, Number 93, USDA, February 2010
} 
sought for use in the Program. The manufacturer holding the WIC contract brand accounted for the vast majority-84\%-of all formula sold by the top three manufacturers. This raises the question if formula support goes against the main goal of encouraging breastfeeding.

Each year there are approximately 4 million births in the States. The majority are fed on infant formula throughout their first years. The U.S. infant formula market accounted for about 3.5 billion dollars in sales in 2007. Infant formula sales by volume have trended downward from 25 billion reconstituted ounces in 2004 to five percent lower in 2007. The infant formula market is highly concentrated. In 2008, three manufacturers accounted for 98 percent of all dollar sales. The Abbott Laboratories, maker of the Similac product line, accounted for 43 percent of the dollar sales. Mead Johnson, maker of the Good Start line accounted for another 15 percent. Most of the remaining 2 percent of infant formula sales was accounted for by PBM Nutritionals, which produces the Bright Beginnings line of infant formulas as well as most of the private-label or store-brand formulas. Each brand offers multiple lines of products to cater various needs of consumers. For example, each brand offers options including milk-based( $80 \%$ of sales), soy-based and protein hydrolysate based products. They also come in different forms such as powder( $83 \%$ of sales), liquid concentrate and ready-to-use $4^{4}$ There are also options on the size of containers.

\footnotetext{
${ }^{4}$ Oliveira et al. The infant formula market: consequences of a change in the WIC contract brand. No. (ERR-124) 44 pp, August 2011
} 


\subsection{Free Samples and the National Campaign}

Evidence has shown that infants grow accustomed to infant formula easily. (Samuels 1993) And when an infant has become accustomed to drinking from a bottle, it will take a lot of time to help her to learn breastfeeding. Likewise, babies accustomed to breastfeeding usually find it difficult to accept bottle nipples and refuse to be fed by bottles. This dependence in feeding method incentivizes the formula companies to early market their products and lock in consumers.

Formula companies use a variety of strategies to market their products. They distribute industry-sponsored formula samples to new mothers in hospitals. These samples come in discharge bags, which may also contain an array of formula coupons. Between $66 \%$ and $72 \%$ of hospitals in the U.S. distribute these free samples, which have been shown to reduce the duration of breastfeeding and lessen exclusive breastfeeding $5^{5}$ Formula companies also market their products in doctor's offices with displays, samples and logos. Advertising formula in hospitals or doctors' offices adds legitimacy to these products. Healthcare facilities provide an ideal venue in which infant formula manufacturers draw in new customers - expectant and new mothers at a time when they can choose a better option: breastfeeding.

Infant formula companies spend about 8 billion dollars (one fifth of industry annual sales) per year marketing infant formula, and they also have a trade group, the International Formula Council (IFC), that does lobbying and other advocacy on behalf of manufacturers. To stop aggressive formula company marketing tactics in hospitals and advocate breastfeeding, public efforts in Massachusetts developed into a national campaign "Ban the Bags" in 2006 countering the practice of distributing

\footnotetext{
${ }^{5}$ Rosenberg et al. Marketing infant formula through hospitals: the impact of commercial hospital discharge packs on breastfeeding, Am J Public Health. 2008 February; 98(2): 290-295.
} 
formula company discharge packs in maternity facilities. With years of efforts, 1029 hospitals and birth centers $(32 \%)$ in Figure 1 have banned free bags..$^{6}$ Rhode Island, Massachusetts, Delaware, Maryland and New Hampshire have become the first five bag-free states.

However, whether banning formula free packs will support and reinforce breastfeeding among mothers remains a question. From 2007 to 2013, breastfeeding ratio slightly increases with the increase of the percentage of bag-free hospitals. No evidence has shown that increase in breastfeeding is caused by the decline in formula discharge packs distribution or the increasing recognition of breastfeeding in population.

${ }^{6}$ Source: https://banthebags.org/bag-free-hospitals/ 


\section{Chapter 4}

\section{Theoretical Model}

In this section, I present a two-period theoretical model where infant formula manufacturer sets non-discriminating price for both periods. I compare breastfeeding ratios when infant formula manufacturer sends out free gift packs or not. I do not differentiate time-consistent preferences from present-biased preferences in my simple two-period theoretical model.

\subsection{The Model}

In each period, consumers make decisions on whether to formula feed or to breastfeed. To breastfeed, mothers need to pay a cost of $C_{0} \in\left(c_{l}, c_{h}\right)$ representing time, efforts and pain associated with breastfeeding. The cost associated with breastfeeding equals $c_{h}$ when formula manufacturer sends out free gift packs, and $c_{l}$ if formula manufacturer does not send out free gifts. $c_{h}$ is higher than $c_{l}$ since breastfeeding mothers need to exercise extra cost to resist the temptation. To purchase infant formula, mothers need to pay the price of infant formula, denoted by $P$. Since mothers have different 
preferences towards how comparable infant formula is to breast milk, I assume that consumers' preferences in the first period (denoted by $\alpha$ ) are uniformly distributed along the Hotelling line $(\alpha \in U[0,1])$ with breastfeeding and formula feeding on the two ends. The transportation cost or the unit preference difference is $t$, which represents the importance of product differentiation. For simplicity, I assume the consumption utility $V$ in each period is big enough so that the market is fully covered. In the first period, consumers choose the feeding method that is optimal for them, taking into account the expectation of the second period utility.

In the second period, consumer preferences (denoted by $\alpha^{\prime}$ ) are again randomly distributed along the Hotelling line and the preference in the second period is independent of the preference in the first period. If a mother decides to switch from breastfeeding to infant formula in the second period, she needs to pay additional cost of $s$ due to baby's dependence in breast milk. However, if a mother decides to feed her baby infant formula in the first period, she can never switch to breastfeeding in the second period. This is because mothers can never resume milk supply if she never starts breastfeeding or stops for a while, indicating the switching cost from infant formula to breastfeeding is positive infinity. In my model, I assume that consumers are forward looking with perfect information and perfect sight. I normalize the cost of production and free gifts to zero. Without loss of generality, I assume the discount factor $\delta$ equals one.

Based on the size of switching cost from breastfeeding to formula feeding $s$, consumers may or may not switch in equilibrium and the formula company solves different profit maximization problems. When $s<C_{0}+t$, consumers may switch in equilibrium when formula price is low enough. When $s \geq C_{0}+t$, consumers will not switch in equilibrium regardless of the formula price being charged. 


\subsection{Low Switching Cost}

I first discuss equilibrium outcomes when switching cost is small and $s<C_{0}+t$. The formula firm selects the equilibrium with or without consumer switch that yields higher profit.

Second Period At any given formula price in the first period, there always exists a threshold $\alpha_{1}$ such that all consumers whose preference in the first period is $\alpha \leq \alpha_{1}$ will choose to breastfeed, and all consumers whose preference in the first period is $\alpha>\alpha_{1}$ will choose formula feeding. Given uniform i.i.d. preferences across time, consumer preferences in the second period $\alpha^{\prime}$ are completely independent with their preferences in the first period $\alpha$. A consumer who purchases infant formula in the first period will continue to formula feed no matter where her preference is located on the Hotelling line in the second period. A consumer who breastfeed in the first period will pay additional switching cost $s$ if she decides to switch to formula feeding. As shown in Figure 2, the threshold between formula feeding and breastfeeding in the second period for consumers who breastfeed in the first period is denoted by $\alpha_{2}$.

The consumer who breastfeeds in the first period is indifferent between breastfeeding and formula feeding in the second period when her preference is $\alpha_{2}$. Therefore

$$
V-C_{0}-t \alpha_{2}=V-P-t\left(1-\alpha_{2}\right)-s
$$

And thus

$$
\alpha_{2}=\frac{P+t+s-C_{0}}{2 t}
$$

Depending on the formula price, breastfeeding mothers may or may not switch in 
the second period. When the equilibrium price is lower than $C_{0}+t-s$, a consumer who breastfeed in the first period will continue breastfeeding if and only if $\alpha^{\prime}<\alpha_{2}$ in the second period. Otherwise, the consumer will switch to formula feeding. When the equilibrium price is higher than $C_{0}+t-s$, then no consumer will switch in equilibrium.

First Period In the first period, consumers observe the formula price and take into account the second period expected utility based on their first period choices. When price is lower than $C_{0}+t-s$, breastfeeding mothers anticipate possible switch in the second period and the utility of choosing breastfeeding in the first period is thus

$U_{B}=V-C_{0}-t \alpha+\int_{0}^{\alpha_{2}}\left(V-C_{0}-t \alpha^{\prime}\right) d F\left(\alpha^{\prime} \mid \alpha\right)+\int_{\alpha_{2}}^{1}\left[V-P-t\left(1-\alpha^{\prime}\right)-s\right] d F\left(\alpha^{\prime} \mid \alpha\right)$

where $V-C_{0}-t \alpha$ is the current utility of breastfeeding in the first period, $\int_{0}^{\alpha_{2}}(V-$ $\left.C_{0}-t \alpha^{\prime}\right) d F\left(\alpha^{\prime} \mid \alpha\right)$ is the expected utility in the second period if the second period preference is located to the left of $\alpha_{2}$ and the consumer continues to breastfeed, $\int_{\alpha_{2}}^{1}\left[V-P-t\left(1-\alpha^{\prime}\right)-s\right] d F\left(\alpha^{\prime} \mid \alpha\right)$ is the expected utility in the second period if the second period preference is located to the right of $\alpha_{2}$ and the consumer switches to formula feeding. Since $\alpha^{\prime}$ and $\alpha$ are completely independent, and $\alpha, \alpha^{\prime}$ are uniformly distributed along the Hotelling line, $d F\left(\alpha^{\prime} \mid \alpha\right)=d \alpha$.

The utility of choosing formula feeding in the first period is

$$
U_{F}=V-P-t(1-\alpha)+\int_{0}^{1}\left[V-P-t\left(1-\alpha^{\prime}\right)\right] d F\left(\alpha^{\prime} \mid \alpha\right)
$$

where $V-P-t(1-\alpha)$ is the current utility of formula feeding in the first period, 
and $\int_{0}^{1}\left[V-P-t\left(1-\alpha^{\prime}\right)\right] d F\left(\alpha^{\prime} \mid \alpha\right)$ is the expected utility of formula feeding in the second period since consumers who breastfeed in the first period cannot switch to breastfeeding.

Consumers with preferences $\alpha_{1}$ are indifferent between breastfeeding and formula feeding, thus

$$
U_{B}\left(\alpha_{1}\right)=U_{F}\left(\alpha_{1}\right)
$$

and the threshold

$$
\alpha_{1}=\frac{1}{2} \alpha^{2}+\alpha_{2}-\frac{s}{t}
$$

where $\alpha_{2}$ is defined in equation 1 .

When formula price is higher than $C_{0}+t-s$ or switching cost $s$ is too high, consumers are aware of the strong lock-in effect for both breastfeeding and formula feeding. The utility of breastfeeding becomes

$$
U_{B}=V-C_{0}-t \alpha+\int_{0}^{1}\left(V-C_{0}-t \alpha^{\prime}\right) d F\left(\alpha^{\prime} \mid \alpha\right)
$$

and the indifferent consumer preference becomes

$$
\tilde{\alpha}_{1}=P-C_{0}+\frac{1}{2}
$$

Infant Formula Pricing The infant formula company determines a single price for both periods. When $s$ is small such that $s<C_{0}+t$, infant formula company decides on price and breastfeeding mothers decide whether or not to switch in the second period based on the price. If $P<C_{0}+t-s$, then consumers may switch 
in equilibrium. The demand for infant formula in the first period is $1-\alpha_{1}$ and the demand for the second period is the sum of consumers who formula feed in the first period $1-\alpha_{1}$ and consumers who switch from breastfeeding to formula feeding in the second period $\alpha_{1}\left(1-\alpha_{2}\right)$. The two-period demand is thus $2-\alpha_{1}-\alpha_{1} \alpha_{2}$. To maximize the total profit, the formula firm attempts to lock in as many as possible consumers in the first period and charge loyal customers a high price in the second period. The investment effect refers to lower price in order to increase demand, and the harvesting effect refers to higher price to exploit customers.

$$
\begin{aligned}
\max _{P} \pi= & \left(2-\alpha_{1}-\alpha_{1} \alpha_{2}\right) P \\
\text { s.t. } & 0 \leq \alpha_{1} \leq 1,0<\alpha_{2} \leq 1 \\
& P<C_{0}+t-s
\end{aligned}
$$

To find out the optimal price, the first order condition yields an implicit function for equilibrium price

$$
P^{*}=\frac{2 t\left(2-\alpha_{1}^{*}-\alpha_{1}^{*} \alpha_{2}^{*}\right)}{\left(1+\alpha_{2}^{*}\right)^{2}+\alpha_{1}^{*}}
$$

where $\alpha_{1}^{*}$ is the breastfeeding ratio in equilibrium in the first period, $\alpha_{2}^{*}$ is the proportion of mothers who continue breastfeeding in the second period in equilibrium. And $\alpha_{1}^{*}$ and $\alpha_{2}^{*}$ are functions of $P^{*}$, formula price in equilibrium. $\alpha_{2}^{*}=\frac{P^{*}+t+s-C_{0}}{2 t}$, $\alpha_{1}^{*}=\frac{1}{2} \alpha_{2}^{* 2}+\alpha_{2}^{*}-\frac{s}{t}$.

Comparative statics can be calculated by taking total differentiation of equation 
4. The comparative static of price with respect to switching cost

$$
\frac{d P^{*}}{d s}=\frac{2 t(d A / d s)}{B}-\frac{2 t A(d B / d s)}{B^{2}}
$$

where $A=2-\alpha_{1}^{*}-\alpha_{1}^{*} \alpha_{2}^{*}$ and $B=\left(1+\alpha_{2}^{*}\right)^{2}+\alpha_{1}^{*}$. Then

$$
\begin{aligned}
\frac{d P^{*}}{d s} & =\frac{B\left(2+2 \alpha_{2}^{*}-B\right)-A\left(1+3 \alpha_{2}^{*}\right)}{2 B^{2}+3 A\left(1+\alpha_{2}^{*}\right)} \\
& =\frac{B\left(1-\alpha_{2}^{* 2}-\alpha_{1}^{*}\right)-A\left(1+3 \alpha_{2}^{*}\right)}{2 B^{2}+3 A\left(1+\alpha_{2}^{*}\right)} \\
& =\frac{2 t\left(1-\alpha_{2}^{* 2}-\alpha_{1}^{*}\right)-P^{*}\left(1+3 \alpha_{2}^{*}\right)}{4 t B+3 P^{*}\left(1+\alpha_{2}\right)}
\end{aligned}
$$

The comparative statics of switching ratio with respect to switching cost is

$$
\frac{d \alpha_{1}^{*}\left(1-\alpha_{2}^{*}\right)}{d s}=\left(1-\alpha_{2}^{* 2}-\alpha_{1}^{*}\right) \frac{d \alpha_{2}^{*}}{d s}-\frac{1-\alpha_{2}^{*}}{t}
$$

and

$$
\frac{d \alpha_{2}^{*}}{d s}=\frac{1}{2 t}\left(1+\frac{d P^{*}}{d s}\right)=\frac{1}{2 t} \frac{B\left(2+2 \alpha_{2}^{*}+B\right)+2 A}{2 B^{2}+3 A\left(1+\alpha_{2}^{*}\right)}>0
$$

Two competing groups of consumers enter formula firm's profit function: one group of consumers $\left(1-\alpha_{1}^{*}\right)$ start formula feeding in the first period and their demand for infant formula sustains in the second period; the other group of switchers $\left(\alpha_{1}^{*}(1-\right.$ $\left.\alpha_{2}^{*}\right)$ ) contribute to the second period demand, the size of which decreases with the the first group. When switching cost is close to zero, the switching ratio $1-\alpha_{2}^{*}$ reaches the highest, and the formula company is incentivized to increase $\alpha_{1}$ and thus increase its price. When switching cost is increasing, the firm benefits less from the switchers 
in the second period and will try to secure its demand by increasing their first period lock-ins. Thus the firm will decrease its price to lower $\alpha_{1}$.

To examine how equilibrium price changes with $C_{0}$, I take total differentiation of equation 4 to solve the comparative statics with respect to $C_{0}$.

$$
\frac{d P^{*}}{d C_{0}}=\frac{B^{2}+3 A\left(1+\alpha_{2}^{*}\right)}{2 B^{2}+3 A\left(1+\alpha_{2}^{*}\right)} \in(0,1)
$$

Then,

$$
\begin{aligned}
& \frac{d \alpha_{2}^{*}}{d C_{0}}=\frac{1}{2 t}\left(\frac{d P^{*}}{d C_{0}}-1\right)<0 \\
& \frac{d \alpha_{1}^{*}}{d C_{0}}=\left(1+\alpha_{2}^{*}\right) \frac{d \alpha_{2}^{*}}{d C_{0}}<0
\end{aligned}
$$

These comparative statics indicate that when breastfeeding cost is higher, demand for infant formula in both the first period $\left(1-\alpha_{1}^{*}\right)$ and the second period $\left(1-\alpha_{1}^{*} \alpha_{2}^{*}\right)$ will increase.

If $P \geq C_{0}+t-s$, then no consumer switches in equilibrium, and the firm tries to maximize the profit

$$
\begin{aligned}
\max _{P} \pi= & 2\left(1-\tilde{\alpha}_{1}\right) P \\
\text { s.t. } & 0 \leq \tilde{\alpha}_{1} \leq 1 \\
& P \geq C_{0}+t-s
\end{aligned}
$$

where $\tilde{\alpha}_{1}$ is defined in equation 3 . The optimal price when conditions are met is

$$
P^{*}=\frac{t+2 C_{0}}{4}
$$


The equilibrium price is then $\max \left\{\frac{t+2 C_{0}}{4}, C_{0}+t-s\right\}$, which is increasing in $C_{0}$.

\subsection{High Switching Cost}

Second, when switching cost from breastfeeding to formula feeding is high $s \geq C_{0}+t$ such that no consumer switches in equilibrium, the firm tries to maximize the profit

$$
\begin{aligned}
\max _{P} \pi= & 2\left(1-\tilde{\alpha}_{1}\right) P \\
\text { s.t. } & 0 \leq \alpha_{1}<1
\end{aligned}
$$

The equilibrium price is $P^{*}=\frac{t+2 C_{0}}{4}$ and the equilibrium profit is $\pi^{*}=\frac{\left(t+2 C_{0}\right)^{2}}{8 t}$.

Recall that under competition with switching costs, firms face two incentives that work in opposite directions (Klemperer 1987). First, firms can harvest a loyal customer by charging higher prices. Second, firms can invest in future loyalty by lowering current prices. Instead of a U-shaped equilibrium price found in Dube et al. (2009) when switching cost is symmetric, in a setting with asymmetric switching cost, equilibrium price of the absorbing choice is monotonically decreasing when the lock-in effect of the other choice is getting stronger. As shown in Figure 3, formula price is highest when switching cost is close to zero since the probability of switching is the highest at this point and the need for a large base of breastfeeding mothers drives the price up. When switching cost is increasing, pursuing switchers becomes less attractive and the formula firm gains more from locking in customers and thus decreases its price. When switching cost gets higher, it becomes difficult to incentivize breastfeeding mothers to switch which requires a very low price, the firm then forgoes the 
switchers and focuses only on locked-in customers. When switching cost is so big that no consumer will switch in equilibrium regardless of formula price being charged, the formula firm maximizes the total profit by maximizing the first period profit.

When breastfeeding cost increases, the formula firm charges higher price and the breastfeeding ratio in both periods decrease. Unless switching cost from breastfeeding to formula feeding is high, the change in prices depends on not only the the change in breastfeeding cost, but also the size of switching cost. In my structural model, I will estimate the difference between $c_{l}$ and $c_{h}$, as well as the size of $s$. Thus I can quantitatively examine the effect of banning free bags of infant formula on breastfeeding ratio. 


\section{Chapter 5}

\section{Data and Descriptive Analysis}

\subsection{Infant Feeding Practice Studies II (IFPS)}

I use Infant Feeding Practice Studies II (IFPS) data collected by Centers for Disease Control and Prevention. The data covers a time period between May 2005 and June 2007. The sample consists of 4,900 pregnant women nationwide, about 2,000 of whom continued with the study through their infants' first year. Each woman received a prenatal questionnaire, followed by a telephone birth screener interview, a neonatal questionnaire mailed about three weeks after the baby's birth and a series of nine postnatal questionnaires approximately monthly throughout the infant's first year of life.

The questionnaires administrated repeated but possibly different topics from month to month. As shown in Table 1, in each questionnaire, food frequency checklist, dietary and herbal supplement intake, breastfeeding and infant formula feeding general information, infant health problems, stopped breastfeeding including age, reasons and breastfeeding attitudes, and WIC participation are asked. Questions regarding 
breastfeeding and formula feeding details are covered in questionnaires distributed in the first, second, fifth and seventh months. Questions with regard to employment status and characteristics, mother's current health and weight and mother's tobacco use and smoking in home are only addressed in the third, sixth, ninth and twelfth months.

The key variables of interest include dummies indicating whether mothers received gift packs from hospital or birth center, whether children enrolled in WIC program, and whether mothers stop breastfeeding and switch to infant formula. Other variables include mother income, race, marital status, employment status and education. The Study further investigates mothers' opinions on breastfeeding compared with infant formula. For example, the prenatal questionnaire asks if mothers believe breastfeeding, formula feeding or mixed feeding is the best way to feed a baby. The questionnaire also asks if mothers agree infant formula is as good as breast milk. In the first, second, fifth, and seventh months, the questionnaire also repeatedly asks when mothers plan to stop breastfeeding and their confidence in breastfeeding as long as they have planned.

It is worth noting that the data suffers limitations and the estimations are subject to bias. First, the sampling bias impairs the representativeness of the dataset. As shown in Table2, Compared with the sample of National Survey of Family Growth (NSFG), IFPS sampled 9.4\% more women above 24 years old, 26.5\% more women with eduction of above high school, and $22.9 \%$ more white mothers. Second, the data does not ask about the specific brand of infant formula purchased and thus eliminate the differences between various brand choices. Consequently, I am unable to further investigate mothers' brand choices of infant formula and study firms' competition in the formula market. 
To find out the price of infant formula from 2005 to 2007, I also use the AC Nielsen Retail Scanner data which consists of weekly price, volume, and store environment information generate from more than 90 participating retail chains across all US markets. Since the IFPS data does not differentiate the brand of infant formula, I thus aggregate the price information in Nielsen Retail data within state and month. I use the weighted average pricing level of all infant formula as the cost associated with formula feeding. However, all dates on the questionnaires in the IFPS dataset have been shifted by a random interval to assure that individuals cannot be identified. To make sure that the relations between dates for each respondent are maintained, all dates for a given respondent were shifted by the same interval. For example, if the random interval for an individual was -10 , then the infant's birth date, the date all questionnaires were completed, the dates the infant was weighed or measured for length, and all other dates are shifted by -10 . Therefore, to match the price information from the Nielsen dataset to individuals in the IFPS dataset based on the birth date of the infants is impossible without knowing the random shift interval for

each individual. I then use the average price level within state to approximate the cost that mothers need to pay for infant formula. I assume an infant consumes $40 \mathrm{oz}$ infant formula on average in a month, then the monthly expenditure of infant formula is on average 47.39 dollars.

\subsection{Summary Statistics}

Next, the demographics of the population who received gift bags of free formula are compared with the group who did not. The purpose of this exercise is to ensure that there are no underlying incentives for mothers to choose birth places according to 
whether or not the hospitals offer free samples of infant formula. If the comparison shows a strong correlation between the acceptance of free samples associated with a certain feature of the receivers, then the distribution of free bags of infant formula is indicative of the quality of hospitals and drives away certain groups of mothers. An alternative explanation is free bags are selectively distributed in hospitals where easily seduced mothers are more likely to patronage.

In Table 3, the population is categorized into two groups based on mothers' reports on whether they received free samples in hospitals. The distribution of income, household size, marital status, race, breastfeeding duration, education, employment status, age of mother, opinions on what is the best way to feed a baby and whether they agree infant formula is as good as breast milk, and whether mother was ever breastfed are compared across these two groups. I further provide the mean difference and a ttest on the hypothesis that mean difference is zero.

As shown in Table 3 , the distribution of the demographics are mostly accepted to be the same across these two groups at a 95\% confidence level. Interestingly, though not significantly, mothers who received free bags in hospitals are more likely to have lower income, non-married relationship, non-white race, lower education, jobs, older age, friendly attitude towards infant formula and no experience of being breastfed. Therefore, the data is suspected of selection of free bags distribution since Breastfeeding Friendly Hospitals often take the lead to ban the bags and these hospitals might be viewed as of high quality. Bearing this in mind, the estimation may suffer from endogeneity problem if free bags end up in hospitals of low quality in poorer neighborhood whose customers are less educated about the benefit of breastfeeding and more negligent in choosing hospitals. However, since mothers demographics and preferences over breastfeeding are mostly observable, the endogeneity problem is not 
a big concern. Table 3 also shows that the breastfeeding duration of mothers who did not receive free bags of infant formula is longer than mothers who received free bags by more or less two weeks.

\subsection{Descriptive Analysis}

To statistically describe the impact of receiving formula gift packs on mothers' breastfeeding duration, I treat stopping breastfeeding as a failure and agents survive if they continue breastfeeding. I then non-parametrically label survival probabilities, equivalently, breastfeeding ratio against age of infants in weeks by whether mothers received formula gift packs in hospitals or birth centers, and by whether free formula was in gift packs The censored cases are accounted for in the analysis denoting mothers who dropped out of the survey before they stopped breastfeeding. Figure 4 and Figure 5 show that mothers who did not receive free formula gift packs tend to breastfeed longer and mothers who did not receive free formula samples in the gift packs are inclined to lengthen their breastfeeding duration. The $95 \%$ confidence intervals for the survival probabilities are included in the graphs for different groups. Though the differences between each leg of the two competing groups are not significant at $95 \%$ confidence bilaterally, the results are encouraging and inspire further investigation.

I further take advantage of the information on mothers' plans on breastfeeding duration collected by the questionnaires in the first, second, fifth, and seventh postpartum months to investigate how likely that mothers are biased to the present. As shown in Figure 6, I compare the histograms of realized breastfeeding duration and planned breastfeeding duration in different questionnaires. The realized breastfeeding

\footnotetext{
${ }^{1}$ If no observations are censored, it is equivalent to the histogram of breastfeeding duration.
} 
durations are consistently shorter than the planned breastfeeding durations, implying that the optimal policy derived at the present for the future period is not the same as the optimal policy when the agent arrives at the future period. This indicates that mothers are not exponentially discounting the future utility. Since the realized breastfeeding durations are consistently shorter than the planned durations, this reveals that consumer preferences are towards the short term cost saving of formula feeding in the contrary to the long run benefit of longer breastfeeding duration. 


\section{Chapter 6}

\section{Reduced Form Results}

To further examine the impact of receiving formula free gifts on breastfeeding duration, I run Cox proportional hazards regression and investigate how hazard ratio changes with covariates of interest. Let $t$ denote the observed time (either censoring time or event time) for subject $i$. In the context of this paper, it represents the time of a mother breastfeeding in the first year. Let $X_{i}=\left\{X_{i 1}, \ldots, X_{i n}\right\}$ denote the vector of covariates for subject $i$. In this paper, the vector includes mothers' and infants' characteristics. Let $C_{i}=0$ denote the subject is censored, $C_{i}=1$ denote the event occurred. The hazard function for the Cox proportional hazard model has the form,

$$
\lambda\left(t \mid X_{i}\right)=\lambda_{0}(t) \exp \left(\beta_{1} X_{i 1}+\ldots+\beta_{n} X_{i p}\right)=\lambda_{0}(t) \exp \left(X_{i} \beta\right)
$$

The conditional probability that the event happens for mother $i$ in period $t$ given that subject $i$ is not censored is

$$
\mathcal{L}_{i}(\beta)=\frac{\lambda\left(t \mid X_{i}\right)}{S\left(t \mid X_{i}\right)}
$$


where $S(t)=1-\int_{0}^{t} \lambda(s) d s$, denoting the cumulative density that the survival time is longer than $t$. And then the joint probability of the realized events conditional upon the occurrence of events is the partial likelihood:

$$
\mathcal{L}(\beta)=\prod_{i: C(i)=1} \frac{\lambda\left(t \mid X_{i}\right)}{S\left(t \mid X_{i}\right)}
$$

Mother demographics are collected in the prenatal questionnaire. I treat household income as a continuous variable ranging from 31 to 57 each representing a range of 5000 dollars. For mother's race, I categorize White and Asian into one group, Black and others into the other group since asian and white mothers tend to share common breastfeeding behavior. Martial status takes values including married, widowed, divorced, separated and never married. I generate a dummy "married" equal to one if mother is married and zero for all other cases. The options for employment status include "Works for someone else full time", "Temporarily unemployed", "Self employed", "Works for someone else part time only", "Retired and not employed", "Disabled, students, etc. and not employed" and "Full time homemaker". I categorize "Works for someone else full time", "Temporarily unemployed" and "Works for someone else part time only" as "Employed by others", "Self employed" and "Full time homemaker" as "Self employed", and "Retired and not employed" and "Disabled, students, etc. and not employed" as "Not labor force". I categorize mother's education into three types: "High school graduate and below", "Some college" and "College graduate and above". The WIC status of children is asked in the first, second, fifth and seventh month questionnaires and do not show much variation for the same individual over time. Whether a mother has received discharge packages with 
infant formula gifts in hospitals is asked in the neonatal questionnaire. It is followed by a question on whether formula samples and formula coupons are included in the discharge bags.

Age of infant when mother returned to work is asked on four different questionnaires, and therefore is consolidated across questionnaires. Because it is possible for a mother to have returned to work, then stopped working for a while, and then returned to work again, the variable is defined as the age of the infant the first time the mother returned to work. The consolidation uses the first answer the mother gave as the value.

Table 4 shows the results of the survival analysis. The hazard ratios are calculated as the exponential of the coefficients, indicating the increase in relative risk of stopping breastfeeding associated with covariates. The household income increases the hazard ratio of stopping breastfeeding since the wealthier the household is, the more discretion that the family has on food spending. Therefore, mothers with higher income may choose infant formula with a higher hazard. White and Asian mothers show stronger preferences towards breastfeeding than black mothers and mothers of other race. Married mothers are more likely to breastfeed longer than mothers of other marital status. Breastfeeding likelihood increases with the education level of mothers and barely changes with the age of mothers or infants. When mothers return to work, the hazard of stopping breastfeeding increases greatly since it gets less friendly and more difficult for breastfeeding mothers. When infants enroll in WIC program, it is more likely that mothers use infant formula since the program provides free infant formula for infants in need. Although the program encourages mothers to breastfeed by providing more supplements and stronger support to mothers who breastfeed, the price reduction effect outperforms the promotion effect. The hazard 
ratio of stopping breastfeeding for mothers who have received gift packs in hospitals and birth centers is 0.38 times higher than mothers who have not received gift packs.

With the belief that breastfeeding mothers tend to stay in the survey longer, the censoring or dropout is not random but correlated with mothers' decisions. While dropout following breastfeeding failure does not bias the estimate of the hazard, censoring before stopping breastfeeding for those mothers who tend to wean early may downward bias the hazard rate of failure. In my structural model, I will model and estimate mothers' attrition behavior and control for possible correlation between mothers' dropout of the Study and breastfeeding failure. 


\section{Chapter 7}

\section{Empirical Model}

In this section, I build an empirical model to estimate the effect of infant formula gift packages. In the demand side, I solve a finite-horizon dynamic problem faced by consumers who maximize the overall utility derived from the consumption of infant formula or breast milk. In the supply side, a firm makes dynamic decisions on pricing strategies to maximize profits. To win over breastfeeding mothers, the firm has incentives to send out discharge packages with free samples and coupons in hospitals to expand the market size of the formula products. Once infants are locked in with infant formula, mothers' breast milk discontinues and the market size for formula will sustain.

\subsection{Consumers}

In each period, mothers make decisions on whether to stop breastfeeding and start using infant formula. Mothers are aware that infant formula is an absorbing state or terminating action. Once infant formula is chosen, it has to be chosen in all the 
following periods. Next, I will define the instantaneous utility of each choice.

Breastfeeding. The per-period utility that consumer $i$ derives from breastfeeding is

$$
U_{i 1 t}=\beta_{0}+X_{i t} \beta_{1}+\gamma \times 1\left\{y_{i t-1}=1\right\}-\phi G_{i}+u_{i}+\epsilon_{i 1 t}
$$

where $\beta_{0}$ is a constant capturing the cost of time and effort associated with breastfeeding compared with formula feeding. $X_{i t}$ represents consumer characteristics in month $t$ postpartum, including infant's age, mother's age, income, race, marital status, employment status, education, whether mother has returned to work, whether infant has ever participated in WIC and whether mother has ever been breastfed. $\gamma$ captures the state dependence or infant's persistence in breastfeeding. When $\gamma>0$, infant earns extra utility from repeated use of breast milk.

$G_{i}$ equals one if mother $i$ has received gift pack of infant formula in hospitals or birth centers. It is subtracted from the utility of breastfeeding because breastfeeding mothers need to exercise costly self control to resist the temptation of infant formula. The model suggests that the temptation effect of infant formula free samples only takes place when mothers have never tried formula feeding.

$u_{i}$ controls for household specific unobserved heterogeneity. Without controlling for the unobserved heterogeneity, the previous period choice $y_{i t-1}$ is correlated with the error term, thus resulting in endogeneity problem. Two potential methods can solve the endogeneity problem and sort out the serially correlated unobserved heterogeneity from the error term. One method assumes $u_{i}$ is a vector of random effects. However, this method assumes away the correlation between the household specific unobserved heterogeneity with household characteristics such as demographics and 
previous period choice. The other method assumes $u_{i}$ is a vector of fixed effects allowing for correlation between the unobserved heterogeneity and household characteristics. This method suffers curse of dimensionality since the number of unobserved fixed effects to estimate equals the number of participants in the sample $N$. Fortunately, the Study asks mothers about their opinions on breastfeeding versus infant formula. In my model, I will control the fixed effect of unobserved persistent heterogeneity by using the information on mothers' preferences towards breastfeeding from the survey data. The information includes mothers' opinions on "the best way to feed a baby" and whether mothers agree "infant formula is as good as breastfeeding". By controlling for the preferences, the rest part of the unobserved heterogeneity is no longer correlated with the lagged term of choice.

In the first period when $t=0$, the utility of breastfeeding is no longer a function of state dependence and other elements remain unchanged.

Infant Formula. The utility that consumer $i$ derives from formula feeding is

$$
U_{i 2 t}=\alpha P_{t} \times 1\left\{W I C_{i t}=0\right\}+\epsilon_{i 2 t}
$$

where $P_{t}$ is the average price of infant formula in month $t . W I C_{i t}$ is a dummy equal to one if child $i$ enrolls in WIC program in period $t$. If a child enrolls in WIC program, then she/he can use designated brand of infant formula for free. Once mothers irreversibly switch to infant formula, their breast milk supply discontinues and breastfeeding is no longer an option. The transition from breastfeeding to formula feeding may take several months. When milk supply is insufficient, mothers may choose to use infant formula as diet supplement thus mix feed their babies. The data documents the month when mothers completely stop breastfeeding. In fact, mothers 
may initiate the switch earlier than the documented time. Therefore, the effect of free gift packages is downward biased in the estimates. $\epsilon_{i t}$ follows generalized extreme value distribution.

Infants also develop state dependence on formula or bottles when they are repeatedly fed with infant formula. In my model, I do not include state dependence on infant formula in the model since infant formula is an absorbing state indicating an infinite positive state dependence.

Attrition Equation. The number of questionnaires mailed decreases slightly across the months because of disqualifications on earlier questionnaires. Even so, the response rates decrease from $83.1 \%$ among 2-month-old infants' mothers to $64.5 \%$ among 12-month-old infants mothers. As a result, 1800 mothers continued with the study through their infants' first year although 4902 completed the prenatal questionnaire initially. If mothers drop out of the Study after they stop breastfeeding, then ignorance of the non-response mothers do not bias the estimates of breastfeeding decision process. However, if mothers quit the study before they stop breastfeeding, then neglecting attrition could result in biased estimates. To deal with problems concerning sample attrition or non-response, I specify the attrition equation as follows,

$$
d_{i t}=1\left\{\mu Z_{i t}+v_{i t} \geq 0\right\}
$$

where $d_{i t}$ equals one when mother $i$ decides to stay in the Study and responds to questionnaire in period $t$ and zero otherwise, $Z_{i t}$ includes infant's age, mother's age, income, race, marital status, employment status, education, preferences over breastfeeding and household size. While the other variables affect decision on breastfeeding as well, household size is exclusive in deciding whether or not mothers drop out of the 
Study. When household size is large, mothers need to take care of the family and relegates the priority of responding to the Study. However, the decision on breastfeeding should not be affected by household size. Likewise, WIC status, whether mother has returned to work, the sex of infant and whether mother has ever been breastfed exclusively influence the decision on breastfeeding. These factors have impacts on mothers' breastfeeding decisions but barely change their minds on whether to continue participating in the Study. To account for the situation that breastfeeding mothers tend to stay in the survey longer, I further control for mothers' preferences towards breastfeeding compared with infant formula using the preferences information in the survey data in the attrition equation. I assume the rest part of the heterogeneity in dropping out of the survey is not related to mothers' breastfeeding decisions.

The State. I have described mothers' decisions on breastfeeding and participation in the Study. I will further discuss the state variables and the transition of state variables. Since the Study sends out questionnaires to pregnant women, and follows up with children's birth and growth in the first year, I can clearly observe each agent's initial status and following choices. When a pregnant woman firstly enters my analysis, I observe a set of initial conditions, including WIC status, mother's age, income, race, marital status, employment status, education, whether mother has ever been breastfed and whether mother has received free samples of infant formula at hospitals. Since the survey only runs a year, I assume that these characteristics remain unchanged during the course of the data. The initial conditions are unlikely to be correlated with the unobserved heterogeneity $u_{i}$. These variables are treated as predetermined and do not evolve in the inter-temporal tradeoffs.

The potentially time-varying state variables include infant's age, mother's last period decision $y_{t-1}$ and whether mother has returned to work. The decision in 
previous period $y_{t-1}$ evolves every period and determines whether the agent enters the absorbing state or accrues further attachment to breastfeeding. Since the length of maternity leave is predetermined by employers, I assume a mother follows the rules and understands when to return to work when pregnant. Therefore, whether a mother returns to work is exogenously determined and perfectly sighted initially. The transition of state variables is thus non-stochastic.

Preferences. A consumer cares about her present and future utility and the inter-temporal value is the sum of the present and discounted future utility. The per period utility is the net reward of consumer's decision on breastfeeding or formula feeding. Each consumer decides on whether to stop breastfeeding in each period to maximize the inter-temporal utility. Different from an exponential discounting model, I adopt the $(\beta, \delta)$-preferences model to describe consumers' potentially timeinconsistent preferences. Consumer preferences are time inconsistent in the sense that mothers may stop breastfeeding earlier than they have planned because the current cost-saving of formula feeding outperforms breastfeeding's long run benefits. Various reasons can urge mothers to stop breastfeeding: needs to return to work, pains of breastfeeding and even temptation from the ease and comfort of using infant formula. These may result in early abandonment of breastfeeding when future rewards of breastfeeding is not perceived as important as the current period disadvantage.

Specifically, all the future utilities are discounted exponentially, while consumers' short-term impatience adds extra weight to the current period utility. The $(\beta, \delta)$ preferences are represented by

$$
W_{t}=U_{t}+\beta \sum_{s=t+1}^{T} \delta^{(s-t)} U_{s}
$$


where $\beta \in(0,1], \delta \in(0,1]$.

$\delta$ is the standard discount factor capturing long-run, time-consistent discounting, and $\beta$ is the present-bias factor capturing short-term impatience. When $\beta=1$ and preferences are not present-biased, the model boils down to the standard discounting model. When $\beta \in(0,1)$, the current period utility is weighted higher than the discounted future utility and consumer preferences are present biased.

Present-Biased Consumers. A feasible strategy in one period is defined as a mapping from states and errors to decisions $\sigma_{t}: S_{t} \times \mathcal{R}^{2} \rightarrow Y$, where $\sigma_{t}\left(S_{t}, \epsilon_{t}\right) \in\{1,2\}$ is the choice of the mother over breastfeeding or formula feeding. To define the continuation value of a present-biased consumer, I first define a time-consistent consumer's value function $V$. The continuation value of a consumer with time-consistent preferences is

$$
\begin{gathered}
V\left(X_{t}\right)=\sup E\left\{\sum_{s=t}^{T} \delta^{(s-t)} U\left(X_{s}, y_{s}, \theta\right) \mid X_{t}\right\} \\
\theta=\left(\beta, \gamma, \alpha, \phi, \mu, \sigma_{1}\right)
\end{gathered}
$$

Since the terminal period is the twelfth month, I can use backward deduction to numerically solve value function. When $t=T$,

$$
V\left(X_{T}\right)=\max _{y_{T} \in\{1,2\}} U\left(X_{T}, y_{T}, \theta\right)+\delta Z\left(X_{T+1} ; \theta\right)
$$

where $Z\left(X_{T+1} \mid y_{T}\right)$ is the continuation value in the terminal period as a function of period $T+1$ state. Specifically, I approximate the continuation value of the terminal period by the following function

$$
Z\left(X_{T+1} ; \theta\right)=\sigma_{1} \times 1\left\{\sum_{t}^{T} 1\left\{y_{t}=1\right\} \geq 6\right\}
$$


That is, if mothers continuously breastfeed longer than six months, infants' and mothers' health in the future will be improved and thus the discounted future utility in period $t+1$ will increase by $\sigma_{1}$.

When $t=T-1, T-2, \ldots$, the continuation value functions are, recursively,

$$
V\left(X_{t}\right)=\max _{y_{t} \in\{1,2\}}\left\{U\left(X_{t}, y_{t}, \theta\right)+\delta E V\left(X_{t+1} ; \theta \mid y_{t}, X_{t}\right)\right\}
$$

Then the strategies for present-biased consumers are

$$
\sigma_{t}^{i}=\arg \max _{y_{t} \in\{1,2\}}\left\{U_{t}\left(X_{t}, y_{t}, \theta\right)+\beta \delta E V\left(X_{t+1} ; \theta \mid y_{t}, X_{t}\right)\right\}
$$

where $V$ is defined in time-consistent equations. The reason that a time-consistent consumer's continuation value enters the decision process of a time-inconsistent consumer is that a present-biased time-inconsistent consumer perceives herself in the future as time consistent. And she believes that future selves will make decisions according to time-consistent preferences. Thus, even though she is biased towards the present with $\beta$ less than one, she naively perceives future $\beta$ 's equal to one in the following periods.

When $t=T$, the strategy in the last period is

$$
\sigma_{T}^{i}=\arg \max _{y_{T} \in\{1,2\}}\left\{U_{T}\left(X_{T}, y_{T}, \theta\right)+\beta \delta Z\left(X_{T+1}, \theta\right)\right\}
$$

Time-Consistent Consumers. A time-consistent consumer has prefect perceptions of her preferences and solve the following problem, when $t=T$, the continuation 
value is

$$
V\left(X_{T} ; \theta\right)=\max _{y_{T} \in\{1,2\}} U\left(X_{T}, y_{T}, \theta\right)+\delta Z\left(X_{T+1}, \theta\right)
$$

When $t=T-1, T-2, \ldots$, the continuation value functions are, recursively,

$$
V\left(X_{t} ; \theta\right)=\max _{y_{t} \in\{1,2\}}\left\{U\left(X_{t}, y_{t}, \theta\right)+\delta E V\left(X_{t+1} ; \theta \mid y_{t}, X_{t}\right)\right\}
$$

Then the strategy for a time-consistent consumer for $t=1,2, \ldots, T-1$ is

$$
\sigma_{t}^{c}=\arg \max _{y_{t} \in\{1,2\}}\left\{U_{t}\left(X_{t}, y_{t}, \theta\right)+\delta E V\left(X_{t+1} ; \theta \mid y_{t}, X_{t}\right)\right\}
$$

The strategy when $t=T$ is

$$
\sigma_{T}^{c}=\arg \max _{y_{T} \in\{1,2\}}\left\{U_{T}\left(X_{T}, y_{T}, \theta\right)+\delta Z\left(X_{T+1}\right), \theta\right\}
$$

The decision process for a mother in equilibrium goes as follows. At the beginning of period $t$, the mother observes her state $S_{t}$ and draws a vector of random shocks associated with breastfeeding and formula feeding. Given her anticipation about her future selves' expected decisions under all possible states, she calculates the continuation value of each choice consisting of realized present utility and discounted future utility using her own discounting factors $(\beta, \delta)$ and chooses the optimal alternative yielding the highest value. For a present-biased mother, she believes her future selves will make decisions according to standard discounting preferences. When the questionnaire arrives, the mother draws the random shock $v_{i t}$ and decides whether to respond to the questionnaire or drop out. If the mother decides to drop out, she is excluded from the Study and no responses will be collected in the future. If the 
mother decides to stay in the study, her decision on breastfeeding is revealed in the data. Then the state variables in period $t+1$ are updated according to the choice made in period $t$ and the process is repeated.

\subsection{Manufacturer}

I develop a simple dynamic supply side assuming that a monopolist maximizes its overall profits. Following Dube et al. (2008) and Shcherbakov (2016), I focus on computing a steady state with constant price. Due to the lack of information on brand competition and vertical competition, the strategic competition between infant formula brands and between manufacturers and retailers are difficult to estimate and out of the question of this paper. This method is fairly stylized and cannot fully account for the changes in the cost structure and market environment across alternative scenarios. However, by using the AC Nielsen retailer scanner data, I can further examine if cost structure or market environment has changed dramatically by examining the infant formula prices and product attributes from 2005 to 2007 . If prices float dramatically, it may imply violent change of market structure, thus focusing on steady state may neglect the importance of underlying market structure change and leads to great distortion.

To explore how much price turbulence has occurred, I describe the price patterns for a few most popular products. Figure 7 show the average prices across nationwide from 2006 to 2010 for Similac Advance milk-based with Iron powder 12.9oz can and Enfamil milk-based 32oz powder in 1992 dollars. They each hold the first and the second biggest market share. As shown in Figure 7, strong seasonal patterns for these two products are demonstrated. Other than seasonal effects, seldom evidence shows 
any dramatic change in market structure or underlying cost before year 2007. In this circumstance, I believe the computation of steady state can provide adequate implication on how state dependence and present-biased preferences may affect breastfeeding ratio in the counterfactual analysis.

Given constant cost and unchanged market environment, the monopolist charges constant price. The unchanged market environment includes unchanged demographics, unchanged brith rates, unchanged set of products, and unchanged political and social environments. The monopolist makes decisions based on the dynamics of the population of consumers, instead of the dynamics of each individual's decision making. When the underlying consumer population and market structure remain unchanged, the dynamics of the state variables and the monopolist price enter steady state and remain constant.

I then specify the problem of a monopolist in the supply side. The potential consumers for the formula firm include incumbent mothers who have not stopped breastfeeding and new cohort of mothers who just have newborns. As the proportion of mothers quitting breastfeeding evolve with formula price and will be locked in with formula since then, the firm faces a dynamic problem nesting the demand dynamics. I assume that the death rate of infants is adequately small such that the body of infants remains balanced through the first year. The new coming customers enter the market in each period at a constant rate, equivalent to the birth rate. I normalize the size of the new entries to 1 by assuming the birth rate is constant and calculate the potential customers, i.e., breastfeeding mothers, in each month postpartum as a percentage of the new entries. I further assume that the marginal cost for distributing gift packs of infant formula is small enough so that the monopolist will send out free samples to all hospitals where discharge bags are not banned. The firm then only 
needs to set a price to maximize the present value of its total profits. The bellman equation is then written as,

$$
V(Y)=w(Y, P)+\delta V(f(Y, P))
$$

where $Y=\left(Y_{1}, Y_{2}, \ldots, Y_{10}\right)$ denotes a vector of the percentages of breastfeeding mothers at the beginning of each postpartum month 1 . Since mothers who have started infant formula will continue with it and their choices are not affected by formula price any more, then how many potential consumers remain in the market is crucial to the firm's decisions. According to the model of the demand side, the conditional probability of breastfeeding depends on the continuation values and varies from month to month postpartum. Therefore, the distribution of breastfeeding mothers at each month postpartum are state variables in the firm's decision making. $Y=f(Y, P)$ is the law of motion denoting how state variables evolve every period in response to formula price. Function $f$ is derived from the demand side and follows $Y_{m+1}=Y_{m} \times \mathcal{P}_{m}$ where $\mathcal{P}_{m}$ denotes the conditional probability that mothers choose to continue breastfeeding when the age of infant is $m$ months old. Following the demand side model,

$$
\mathcal{P}_{m}=\frac{\exp \left(\bar{W}_{1 m}\right)}{\exp \left(\bar{W}_{1 m}\right)+\exp \left(\bar{W}_{2 m}\right)} .
$$

The proportion of formula feeding mothers at $m$ months postpartum are the sum of formula feeding mothers at $m-1$ months postpartum and breastfeeding mothers at $m-1$ months postpartum who switch to formula feeding at $m$ months postpartum. It

\footnotetext{
${ }^{1}$ Since no questionnaire is sent out in the eighth and the tenth month postpartum in IFPS, I correspondingly assume the monopolist is making decisions irrespective of consumers' decisions in the eighth and the tenth month postpartum.
} 
is the complement to mothers who continue breastfeeding in month $m$. Therefore the percentage of formula feeding mothers at the beginning of $m+1$ month postpartum is $1-Y_{m+1}=1-Y_{m} \times \mathcal{P}_{m}$. In the state vector, the first element is predetermined, $Y_{1}=1 . P=\sigma(Y)$ denotes the firm's pricing strategy depending on the distribution of breastfeeding mothers from the first month postpartum to the end of the first year. $w(Y, P)$ denotes the current period profit given the state vector $Y$ and price $P$.

$$
w(Y, P)=\left[\sum_{m=1}^{10} 1-Y_{m} \times \mathcal{P}_{m}\right](P-c)
$$

where $c$ denotes the marginal cost of production. The demand is the sum of all formula feeding mothers in each postpartum month in the first year. $\delta$ is the discount factor. I assume the discount factor for the firm is the same as the long-term discount factor for consumers.

Differentiating the Bellman equation with respect to both $P$ and $Y$ and applying the envelope theorem yields a set of three equations,

$$
\begin{gathered}
\frac{\partial w}{\partial P}+\delta\left[\frac{\partial f}{\partial P}\right]^{t} \lambda=0 \\
\frac{\partial w}{\partial Y}+\delta\left[\frac{\partial f}{\partial Y}\right]^{t} \lambda=\lambda \\
Y=f(Y, P)
\end{gathered}
$$

where $\lambda$ denotes $\frac{\partial V}{\partial Y}$ indicating the vector of derivatives of the value function $\mathrm{V}$ with respect to the state vector.

If $\left(I-\delta\left[\frac{\partial f}{\partial Y}\right]^{t}\right)$ is invertible, $\lambda$ is solvable and substitute it out of the equations 
can simplify the system of three equations to two equations,

$$
\begin{gathered}
\frac{\partial w}{\partial P}+\delta\left[\frac{\partial f}{\partial P}\right]^{t}\left(I-\delta\left[\frac{\partial f}{\partial Y}\right]^{t}\right)^{(-1)} \frac{\partial w}{\partial Y}=0 \\
Y=f(Y, P)
\end{gathered}
$$

Then the only unknown parameter is the marginal cost $c$.

I next provide formulas for each of the terms in the equations. First, the derivative of single period payoff with respect to price is

$$
\frac{\partial w}{\partial P}=\sum_{m=1}^{T}\left(1-Y_{m} \times \mathcal{P}_{m}\right)-(P-c) \sum_{m=1}^{T} Y_{m} \frac{\partial \mathcal{P}_{m}}{\partial P}
$$

where

$$
\frac{\partial \mathcal{P}_{m}}{\partial P}=\frac{\partial\left(\frac{\exp \left(\bar{W}_{1 m}\right)}{\exp \left(\bar{W}_{1 m}\right)+\exp \left(\bar{W}_{2 m}\right)}\right)}{\partial P}=-\frac{\partial \bar{W}_{2 m}}{\partial P} \mathcal{P}_{m}\left(1-\mathcal{P}_{m}\right)
$$

Since consumers form expectations about future prices based on today's price, I assume consumers expect future prices to be the same as today's price and the change of price in the current period will affect not only today's choice but only future's choices and thus the continuation value in the current period. Specifically, since infant formula is the absorbing state, the continuation value of formula feeding for mothers in $m$ th month postpartum is the sum of the discounted utility of formula feeding starting from the current period $m$ to the end of the first year. Then the partial derivative of the continuation value with respect to the price is thus the sum of the discounted derivatives of the utilities of formula feeding with respect to price from the current month $m$ to the end of the first year. And the derivatives for present-biased 
consumers postpartum month $m=1,2, \ldots, T-1$ are

$$
\frac{\partial \bar{W}_{2 m}}{\partial P}=\alpha\left(1+\beta \sum_{s=1}^{T-m} \delta^{s}\right)
$$

When $m=T$, the derivative equals $\alpha$. For time-consistent consumers, $\beta=1$.

Second, the evolvement of state variables follows the law of motion $Y_{m}=Y_{m-1} \times$ $\mathcal{P}_{m-1}$ and thus

$$
\begin{aligned}
& \frac{\partial f}{\partial P}=\left[\begin{array}{c}
0 \\
\alpha \mathcal{P}_{1}\left(1-\mathcal{P}_{1}\right) \\
\alpha Y_{2} \mathcal{P}_{2}\left(1-\mathcal{P}_{2}\right) \\
\cdots \\
\alpha Y_{9} \mathcal{P}_{9}\left(1-\mathcal{P}_{9}\right)
\end{array}\right] \\
& \frac{\partial f}{\partial Y}=\left[\begin{array}{cccccc}
0 & 0 & 0 & \ldots & 0 & 0 \\
\mathcal{P}_{1} & 0 & 0 & \ldots & 0 & 0 \\
0 & \mathcal{P}_{2} & 0 & \ldots & 0 & 0 \\
0 & 0 & \mathcal{P}_{3} & \ldots & 0 & 0 \\
\ldots & & & & & \\
0 & 0 & 0 & \ldots & \mathcal{P}_{9} & 0
\end{array}\right]
\end{aligned}
$$

Lastly, the derivatives of single period profit functions with respect to the state vari- 
ables follow

$$
\frac{\partial w}{\partial Y}=\left[\begin{array}{c}
-\mathcal{P}_{1} \\
-\mathcal{P}_{2} \\
-\mathcal{P}_{3} \\
\cdots \\
-\mathcal{P}_{10}
\end{array}\right](P-c)
$$

I then use equation 11 to back out firm $\operatorname{cost} c$, and use iteration to find out the fixed point of equation 11 and 12 to simulate firm's choice in a counterfactual scenario. 


\section{Chapter 8}

\section{Estimation Strategy}

In this section, I will discuss the estimation strategy for the demand side. Specifically, I use Maximum Likelihood Estimation to estimate the model. I will further discuss identification of the estimators.

\subsection{Maximum Likelihood Estimation}

Since each consumer faces a finite horizon dynamic problem, I use backward deduction to define the conditional value function of each choice recursively and thus the conditional choice probabilities as a function of conditional values. According to Holtz and Miller (1993), when at least one choice is terminating, the dynamic problem can be solved without specifying the conditional values but only the conditional choice probabilities. However, since I further investigate mothers' present-bias in the intertemporal tradeoffs, I still use backward deduction to estimate the discount factors. Next, I will illustrate the estimation strategy for present-biased consumers.

To define the conditional values for a present-biased consumer, I firstly define the 
conditional value of consumers with standard discounting $V_{y}$. Since infant formula is the absorbing state, the value of $y_{t}=2$ is just the discounted utility derived from the cost of infant formula interacted with children's WIC status and unobserved heterogeneity. This implies that the conditional value of stopping breastfeeding is

$$
V_{2}\left(X_{t} ; \theta\right)=E\left\{\sum_{s=t}^{T} \delta^{(s-t)} U\left(X_{s}, y_{s}=2, \theta\right) \mid X_{t}\right\}
$$

The conditional value of breastfeeding is defined as the sum of the present utility and the expected discounted future utility.

$$
V_{1}\left(X_{t} ; \theta\right)=U\left(X_{t}, y_{t}=1, \theta\right)+\delta E V\left(X_{t+1} ; \theta \mid y_{t}=1, X_{t}\right)
$$

where $E V$ is defined as in equation. When the error term follows Generalized Extreme Value distribution, the expected maximum value has a closed form $E V\left(X_{t}\right)=$ $\ln \left(\exp \left(\bar{V}_{1}\left(X_{t}\right)\right)+\exp \left(\bar{V}_{2}\left(X_{t}\right)\right)\right)$ where $\bar{V}_{y}$ is defined as $V_{y}-\epsilon_{y}$.

With the definition of conditional value functions for time-consistent preferences, the conditional values for present-biased consumers are

$$
\begin{gathered}
W_{1}=U\left(X_{t}, y_{t}=1, \theta\right)+\beta \delta E V\left(X_{t+1} \mid y_{t}=1, X_{t}\right) \\
W_{2}=U\left(X_{t}, y_{t}=2, \theta\right)+\beta E\left\{\sum_{s=t+1}^{T} \delta^{(s-t)} U\left(X_{s}, y_{s}=2, \theta\right) \mid X_{t}\right\}
\end{gathered}
$$

Given that the subject stays in the study $d_{i t}=1$, the conditional choice probabilities follow

$$
\operatorname{Prob}\left(y_{i t}=1 \mid y_{i t-1}=1, d_{i t}=1\right)=\frac{\exp \left(\bar{W}_{1}\left(X_{t}\right)\right)}{\exp \left(\bar{W}_{1}\left(X_{t}\right)\right)+\exp \left(\bar{W}_{2}\left(X_{t}\right)\right)}
$$




$$
\operatorname{Prob}\left(y_{i t}=2 \mid y_{i t-1}=1, d_{i t}=1\right)=\frac{\exp \left(\bar{W}_{2}\left(X_{t}\right)\right)}{\exp \left(\bar{W}_{1}\left(X_{t}\right)\right)+\exp \left(\bar{W}_{2}\left(X_{t}\right)\right)}
$$

where $\bar{W}_{y}=W_{y}-\epsilon_{y}$.

Alternatively, the conditional choice probabilities for a time-consistent subject is,

$$
\begin{aligned}
& \operatorname{Prob}\left(y_{i t}=1 \mid y_{i t-1}=1, d_{i t}=1\right)=\frac{\exp \left(\bar{V}_{1}\left(X_{t}\right)\right)}{\exp \left(\bar{V}_{1}\left(X_{t}\right)\right)+\exp \left(\bar{V}_{2}\left(X_{t}\right)\right)} \\
& \operatorname{Prob}\left(y_{i t}=2 \mid y_{i t-1}=1, d_{i t}=1\right)=\frac{\exp \left(\bar{V}_{2}\left(X_{t}\right)\right)}{\exp \left(\bar{V}_{1}\left(X_{t}\right)\right)+\exp \left(\bar{V}_{2}\left(X_{t}\right)\right)}
\end{aligned}
$$

where $\bar{V}_{y}=V_{y}-\epsilon_{y}$. And the likelihood contributed by individual $i$ is the probability of dropping out of the study or the probability of staying in the study and stopping breastfeeding or continuing breastfeeding:

$$
\begin{aligned}
L_{i}(\theta)= & \prod_{t=1}^{T}\left\{\operatorname{prob}\left(y_{i t}=1 \mid d_{i t}=1\right)^{1\left\{y_{i t}=1\right\}} \operatorname{prob}\left(y_{i t}=2 \mid d_{i t}=1\right)^{1\left\{y_{i t}=2\right\}}\right. \\
& \left.\operatorname{prob}\left(d_{i t}=1\right)\right\}^{1\left\{d_{i t}=1\right\}} \operatorname{prob}\left(d_{i t}=0\right)^{1\left\{d_{i t}=0\right\}}
\end{aligned}
$$

Therefore, the log likelihood function is

$$
\begin{aligned}
\log L(\theta) & =\sum_{d=1} 1\{y=1\} \log \operatorname{prob}(y=1)+1\{y=2\} \log \operatorname{prob}(y=2) \\
& +\log \operatorname{prob}(d=1)+\sum_{d=0} \log \operatorname{prob}(d=0)
\end{aligned}
$$

Then I use the Maximum Likelihood Method to estimate the demand side. 


\subsection{Identification}

The covariation of consumer demographics, WIC status, working status, preferences over infant formula, procession of free gift packs and infant formula price with consumer choice will help identify demand parameters. The covariation of consumer demographics, working status and preferences over infant formula with participants' attrition behavior can help identify the attrition equation.

The identification of state dependence requires careful discussions. First, since formula feeding is an absorbing state (that is, the state dependence for formula feeding is positive infinity), the state dependence to estimate is only present when mothers choose to continue breastfeeding. The indicator denoting breastfeeding in the previous period is always one in the breastfeeding utility since a formula feeding mother can never switch to breastfeeding. Thus, $\gamma$ is always present in the utility function for breastfeeding as well as the constant parameter except in the first period. The identification of structural state dependence $\gamma$ from the constant parameter in breastfeeding utility comes from consumer choices in the first month when infants do not develop any state dependence. Second, the structural state dependence is separately identified from the persistent preferences over infant formula by controlling for mothers' preferences investigated in the survey. However, infants may have persistent taste preferences over breastfeeding which is not captured by mothers' opinions on breastfeeding versus infant formula.

The identification of discounting parameters is discussed in previous literature. Fang and Silver (2009) illustrate three aspects from which the present-biased preferences can be identified. Fang and Silver (2006) prove that with three or more periods of data, an exponential discounting model could not rationalize the choice probabil- 
ities if the data were generated by a model of $(\beta, \delta)$ discounting. Intuitively, in my model, mothers' choices in each period provide information on the continuation values and conditional choice probabilities, two of whom are compatible with each other. In my model, the far-off benefit of breastfeeding on children's health is contained in $\sigma_{1}$. If mothers breastfeed for at least six months, the continuation value at the terminal age increases by $\sigma_{1}$. However, for present-biased mothers, they are impatient to breastfeed long enough even though they are aware that breastfeeding longer can improve children's health and their own benefits in the long run. 


\section{Chapter 9}

\section{Estimation Results}

In this section, I will present the estimation results for both present-bias model and time-consistent model and discuss the economic interpretation of the coefficients. The Likelihood ratio test prefers the present-bias model in the demand side despite fairly consistent estimates compared to the time-consistent model.

\subsection{Demand Side}

Table 5 presents demand estimation results for both present-bias and time-consistent models. Compared with the estimation of present-biased preferences in other literature, the present-bias factor for infant mothers is much smaller than other estimates ${ }^{1}$ According to Table 5, the present-bias factor for infant mothers is 0.20 , and the longterm discount factor is estimated to be 0.932 The one month ahead discount factor

\footnotetext{
${ }^{1}$ Labison et al. (2007) find a present-bias discount factor of 0.703. Paserman (2008) find 0.40 time impatience in low wage workers. Fang and Silverman (2009) estimate the present-bias factor to be 0.338. Fang and Wang (2015) show a present-bias factor as 0.508 .

${ }^{2}$ The long-term discount factor is comparable to the estimation in other literature. Labison et al. (2007) find the long-term discount factor is 0.96. Paserman (2008) estimates the long-term discount factor to be 0.95. Fang and Silverman (2009) estimate the long-term discount factor to be 0.88 .
} 
is thus $0.20 \times 0.93=0.19$. The long-term discount factor in this study has a different interpretation compared to other literature who report annualized estimates. In my study, infant mothers decide on when to stop breastfeeding in the first year of their babies. They are forward looking insofar as within the period of the dynamic problem when infants are less than one year old. Therefore, the long-term discount factor is in respect of how mothers making decisions on breastfeeding discount the next month utilities. And there is no need to annualize the long-term discount factor in this sense. The estimated discount factor in the time-consistent model is 0.39 .

The state dependence parameter is estimated to be 0.82 in the present-bias model and 1.12 in the time-consistent model, implying that infants are dependent on breast milk and develop consumer inertia. When prices are fixed, I further examine the effect of state dependence on breastfeeding ratio in both models. Specifically, I assume infants' state dependence on breastfeeding is absent, that is, $\gamma=0$. Then I simulate the predicted conditional probability of continuing breastfeeding for each individual in each postpartum month. The probability that individual $i$ continues breastfeeding until period $t$ is thus the product of the conditional probabilities of breastfeeding in the first $t$ periods. The breastfeeding ratio in period $t$ is then the sum of the probability of breastfeeding across individuals who survive in period $t$ and choose to continue breastfeeding. As shown in Figure 9, the timeline for breastfeeding ratio predicted by the present-biased preferences model starts from $70.83 \%$ in the first month postpartum, decreases to $47.15 \%$ in the sixth month and $27.82 \%$ at the end of the first year, the trend in which is close to the anecdotal breastfeeding ratio timeline in the United States. The starting point if no state dependence is present falls to $35.19 \%$, breastfeeding ratio in the sixth month is $1.21 \%$, and finally ends in $0.21 \%$. It is shown that the state dependence increases breastfeeding ratio greatly 
when firms' prices are fixed, which incentivizes firms to send out free gift packs to lock in customers early.

The effect of free gift packs of infant formula only plays a role when mothers are still breastfeeding. The effect is estimated to be 0.06 in the present-bias model and 0.07 in the time-consistent model, indicating that the presence of free gifts decreases the utility of breastfeeding. The coefficients are not very significant but the simulation with no gift packs shows that breastfeeding ratio will slightly increase if all hospitals go bag free in Figure 10. The present-bias model predicts that the breastfeeding ratio in the first month will increase from $70.83 \%$ to $72.97 \%$, and from $47.15 \%$ to $50.51 \%$ in the sixth month, and from $27.82 \%$ to $30.90 \%$ in the last month of the first year. In the next section, I will perform counterfactual analysis in a simple supple side setting, where the monopolist will change the price when all hospitals ban the bags.

The incremental values for breastfeeding at least six months is 6.12 in the presentbias model and 7.86 in the time-consistent model. The estimates represent the discounted value of future utility based on children's and mothers' future health as a result of breastfeeding duration. In line with the recommendations from the WHO, mothers who breastfeed at least six months can greatly improve children's health and their own status in the future.

The full results are presented in Table 6. As shown in the table, consumers are rather sensitive to formula price since they are forward looking and anticipate the lock-in effect of infant formula. The constant term measures breastfeeding cost for the baseline group. The baseline group consists of mothers who have low level of income and education, relatively young, and express inclination to infant formula. The negative constant indicates that breastfeeding is viewed inferior to formula feeding among the baseline group. It also measures the pain and efforts to consume when 
breastfeeding. If long-term benefits of breastfeeding are not taken into account, the cost of breastfeeding will less breastfeeding ratio immediately.

Participation in the WIC program increases the recognition of the benefits of breastfeeding among mothers due to the programs' purpose and efforts of promoting breastfeeding. When a family enrolls in the program, the mother often receives breastfeeding supports and aids such as counseling, breastfeeding educational materials and even free breast pumps. These supports and assistance encourage mothers to breastfeed longer and reduces the cost of breastfeeding. However, the formula price reduction effect may discourage breastfeeding since mothers are provided with free designated brand-name infant formula. The net effect of WIC participation on breastfeeding is thus $\beta_{W I C}-P * \alpha=-0.36$, indicating that despite the efforts to promote breastfeeding, the price reduction effect drives more participating mothers to switch to infant formula.

Returning to work makes breastfeeding more difficult and thus adds more cost to breastfeeding. Families with higher income have higher budgets and find infant formula more rewarding. Married couples are more likely to breastfeed their babies. Mothers with higher education are inclined to breastfeed longer although the effect is only prominent for college graduates. Mothers in later age cohorts tend to breastfeed longer and mothers who were ever breastfed are also more likely to breastfeed their own babies. Mothers with strong preferences towards breastfeeding truly breastfeed longer, evidencing the credibility of the survey data. It also shows that the preferences survey data control for persistent tastes or fixed effects to a great extent, validating the estimation of the structural state dependence. Breastfeeding cost decreases with the increase in infant's age, indicating that new mothers always find it most difficult to breastfeeding at the beginning; once they learn how to latch on, how to deal with 
engorgement, and how to adapt to the body change, they will find breastfeeding easier. Hence, more resources should be invested in reducing the learning cost of breastfeeding and help mothers to get used to breastfeeding.

Figure 8 compares the estimated model's predicted breastfeeding ratio to the actual breastfeeding ratio in the data. The model's predicted breastfeeding ratio is simulated using parameters estimated under either present-bias and time-consistent assumptions. The predicted breastfeeding ratio through the first year of infant matches the data reasonably well. The prediction assumes the correct trend and match the levels of the data quite closely.

My estimation indicates a high level of short-term impatience; the one-monthahead discount factor is 0.19. A natural question to ask is whether the behavior of mothers with such limited patience is practically different from that of agents with no concern for the future. To shed some light on this issue, I simulate behavior for the case where, holding all other parameters constant at their estimated values, agents are assumed to be completely myopic $(\beta=\delta=0)$. It is not simulation from the estimates of a completely myopic model (with $\beta$ and $\delta$ restricted to zeros); rather, it merely reflects how behavior would look in the previously estimated environment if agents were completely myopic. The breastfeeding ratio for this simulation is also displayed in Figure 8. The behavior of myopic consumers is significantly quantitatively different. Therefore, despite the short-term impatience in consumers, mothers' behavior is different from that of myopic case.

The attrition equation estimation is shown in Table 7. To take into account the situation that breastfeeding mothers tend to stay in the survey longer, I also control for mothers' preferences over breastfeeding compared to infant formula in the attrition equation. Bigger household size, higher income and employment increase 
the probability that a mother drops out of the Study.

\subsection{Supply Side}

I use equation 11 in the model to back out the cost parameter for the monopoly firm. I first calculate the derivatives of the conditional probabilities of continuing breastfeeding with respect to price using the parameters estimated from the demand side. I then calculate the marginal cost that rationalizes the observed price and breastfeeding ratio. The price I use is the price of infant formula that an infant consumes on average in a month.

I estimate the cost parameter under the assumptions that consumer preferences are present-biased or time-consistent. The marginal cost for the monopolist when consumer preferences are time-consistent is estimated to be 41.08 dollars, approximately $86.68 \%$ of the price, while the marginal cost for the monopolist when consumer preferences are present-biased is 23.70 dollars, approximately $50.11 \%$ of the price.

The mark-up is greater when consumers are present-biased since they are more likely to switch to infant formula and locked-in in this scenario. When consumers display high degree of short-term impatience, the "bargain-then-rip-off" strategy is reinforced since consumers underestimate the lock-in effect. To examine whether the formula firm would take more advantage and exploit consumers when they are present-biased, I run simulation to compare infant formula company's pricing policies when consumer preferences are present biased versus time consistent. I fix the marginal cost at the estimated value in the time-consistent model. All other parameters in the demand side are set to the estimated values under the assumption of present-biased agents. I simulate the price that the monopolist faced with a constant 
marginal cost would charge when consumer preferences are present biased and compare the simulated price with the real price in the data. The simulated price when consumer preferences are present biased is 75.45 dollars, higher than the price when consumer preferences are time-consistent. The comparison between these two models indicates that when consumers are present biased, the "bargain-then-rip-off" strategy is reinforced and the formula firm sets higher price. 


\section{Chapter 10}

\section{Counterfactual Analysis}

I conduct two sets of counterfactual analysis assuming consumers have present-biased and time-consistent preferences. In both analyses, I examine the breastfeeding ratio and consumer welfare changes. In the first counterfactual analysis, I solve for monopolist steady state price and consumer breastfeeding decisions in a world when all hospitals ban free packs of infant formula. I find that the monopolist will lower price and the breastfeeding ratio will increase in the first year and consumers are better off from three sources. In the second analysis, I assume state dependence in breast milk is not present and simulate the counterfactual price and breastfeeding ratio. I find that the monopolist will increase formula price and the breastfeeding ratio will decrease, corresponding to my finding in the theoretical model. However, consumers will be worse off if state dependence is not present.

The estimation strategy to carry out counterfactual analysis follows four steps:

1. Pick $Y_{0}$ and $P_{0}$.

2. Solve for $P_{1}$ given $Y_{0}$ in equation 11 .

2. Solve for $Y_{1}$ given $P_{1}$ in equation 12 . 
4. Repeat until $\left|P_{k}-P_{k-1}\right|<$ tolerance.

In the first step, I use the current price and the vector of the percentages of breastfeeding mothers in each month postpartum in the first year as the initial values. In the second step, I first simulate $\mathcal{P}_{m}$, the conditional choice probability of continuing breastfeeding, under the assumptions in the counterfactual analysis. The marginal cost from the supply side is measured from the estimation, then the new

equilibrium price in the counterfactual world is inferred from the simulated mark-up using equation 11. Given the simulated price, in the third step, I update the vector of the percentages of breastfeeding mothers for the next iteration using equation 12 . Finally, the iteration stops when the difference between the prices of two consecutive iterations is smaller than the tolerance.

\subsection{All Hospitals "Ban the Bags"}

In this section, I simulate the counterfactual scenario when all hospitals "ban the bags" of free infant formula gifts. I assume parameter $\phi$ associated with gift packs in the demand model to be zero. It is equivalent to setting the indicator of receiving free gift packs to zero. If all hospitals do not allow the distribution of infant formula free gifts, the infant formula companies are predicted to lower their prices to attract consumers since the manufacturers lose the venues where they seduce and lock in consumers at an early stage. The simulated price in the counterfactual scenario is 45.85 dollars when consumer preferences are present-biased and 47.18 dollars when consumer preferences are time-consistent.

I further simulate the breastfeeding ratio in each month of the first postpartum year in equilibrium in the counterfactual scenario when all hospitals "ban the bags". 
In Figure 12, I depict the counterfactual breastfeeding ratio timeline as well as the observed breastfeeding ratio timeline in the real world for both circumstances when consumer preferences are present-biased and time-consistent. The breastfeeding ratio when consumer preferences are present-biased starts from $72.83 \%$ in the first postpartum month, drops to $49.93 \%$ in the sixth postpartum month and $30.19 \%$ in the twelfth postpartum month. The breastfeeding ratio when consumer preferences are time-consistent starts from $71.89 \%$ in the first postpartum month and then decreases to $46.52 \%$ in the sixth postpartum month and $28.46 \%$ in the end of the first year. The breastfeeding ratio in the counterfactual scenario is greater than the observed breastfeeding ratio in the real world by less amount than that in Figure 10 when price is fixed. However, the analysis shows that if all hospitals ban the free bags of infant formula gifts, it will persistently increase the breastfeeding ratio by $2.0 \%$ to $2.8 \%$. Throughout the first year, each mother will save on average ten dollars from the decrease in infant formula consumption, fifteen dollars from the decrease in infant formula price, and receive higher payoff from longer breastfeeding duration at the end the first year.

Under present-bias assumption, when all hospitals ban free formula gift bags, consumer welfare increases by $38.86 \%$, the monopolist's profit decreases by $3.20 \%$. Switching ratio in each period decreases despite lower formula price, thanks to less marketing as shown in Figure 13(a).

\subsection{Without State Dependence}

When state dependence is absent, I assume parameter $\gamma$ in the demand side equals zero. Thus, mothers are more likely to switch to infant formula and infants will not 
grow addiction to breast milk. Intuitively, infant formula manufacturer has more bargaining power and will increase the price. The counterfactual analysis shows that the price that formula company will charge in a world where no state dependence is present in breastfeeding utility is 59.41 dollars when consumer preferences are presentbiased and 49.14 dollars when consumer preferences are time-consistent. And the mark-ups increase dramatically due to the absence of state dependence.

I further simulate breastfeeding ratio in equilibrium in the counterfactual scenario when state dependence is absent using both present-bias model and time-consistent model. Figure 11 shows that breastfeeding ratio will decrease by less than the amount shown in Figure 9 where price is fixed. Breastfeeding ratio when consumer preferences are present-biased starts from $54.92 \%$ in the first postpartum month, drops to $16.89 \%$ in the sixth postpartum month and $6.07 \%$ in the twelfth postpartum month. Breastfeeding ratio when consumer preferences are time-consistent starts from $66.72 \%$ in the first postpartum month and then decreases to $18.82 \%$ in the sixth postpartum month and $6.25 \%$ in the end of the first year. Breastfeeding ratio in the counterfactual scenario when state dependence is not present is lower than the observed breastfeeding ratio in the real world. This finding indicates the same conclusion drawn from the theoretical model: when the switching cost from formula feeding to breastfeeding is increasing, formula price will increase and breastfeeding ratio will decrease. Therefore, consumers will be worse off if infants do not develop addiction to breast milk because of higher formula prices and lower breastfeeding rate.

Due to price increase and enlarged market size, firm profit greatly increases by as much as $34.89 \%$ under present-bias assumption. Switching ratio significantly jumps up due to the lack of state dependence in breast milk as shown in Figure $13(\mathrm{~b})$. 


\section{Chapter 11}

\section{Conclusion}

My work has facilitated the understanding of mothers' feeding practice and how free packs of infant formula has affected mothers' decisions. The dollar value for the free gift pack is as low as 1 to 2 dollars. However, they sit in houses and tempt mothers into long-term dependence on infant formula leading to much more expenditure. I find that if infant formula free gifts are banned in all hospitals, the breastfeeding ratio each month in the first postpartum year consistently increases by around $2.0 \%$ due to less temptation and higher formula price. The increase in breastfeeding ratio is equivalent to twenty five dollars of saving in expenditure for each consumer in one year, and welfare increase of health improvement due to longer breastfeeding duration. Under present bias assumption, consumer welfare will increase by $38.86 \%$ and the monopolist's profit will decrease by $3.20 \%$. Therefore, commercial discharge bags with free infant formula samples should be banned to increase social welfare.

The study also shows that a stable family, higher education and more experience with breastfeeding can enhance mothers' acknowledgement of the benefits of breastfeeding. Therefore, breastfeeding educational material, adequate assistance 
and supports are essential in promoting breastfeeding among mothers, especially new mothers. New mothers always find it most difficult to start breastfeeding; once they learn how to latch on, how to deal with engorgement, and how to adapt to the body change, they will find breastfeeding not as difficult as it is at the beginning. Hence, more resources should be invested in assisting new mothers to learn and get used to breastfeeding. The government subsidized program WIC is successful in lowering breastfeeding cost and providing breastfeeding aids. However, considering the formula price reduction effect, the net effect of WIC participation is not palatable.

The present-bias model captures time-inconsistency in consumer preferences. The short-term discount factor is estimated to be 0.20 and the long-term discount factor is estimated to be 0.93. The "bargain-then-rip-off" strategy is reinforced to take advantage of consumers' short-term impatience. In my model, I have not differentiated between completely naive, partially native and sophisticated consumers as described in Fang and Silver (2006) and Fang and Wang (2015). Consumers in my model are all assumed to be completely naive. An agent is partially naive if the self in every period underestimates the present-bias of her future selves, believing that her future selves' present-bias is $\tilde{\beta} \in(\beta, 1)$. A sophisticated consumer perfectly understands her future selves' present-bias and $\tilde{\beta}=\beta$. In the IFPS survey, questionnaires ask when mothers plan to stop breastfeeding and how confident they are to breastfeed until they have planned. In my future research, This information can help identify $\tilde{\beta}$ which determines when mothers plan to stop breastfeeding. 


\section{Chapter 12}

\section{Appendix}

\section{$12.1 \quad$ Figures}

Figure 1: Bag Free Hospitals

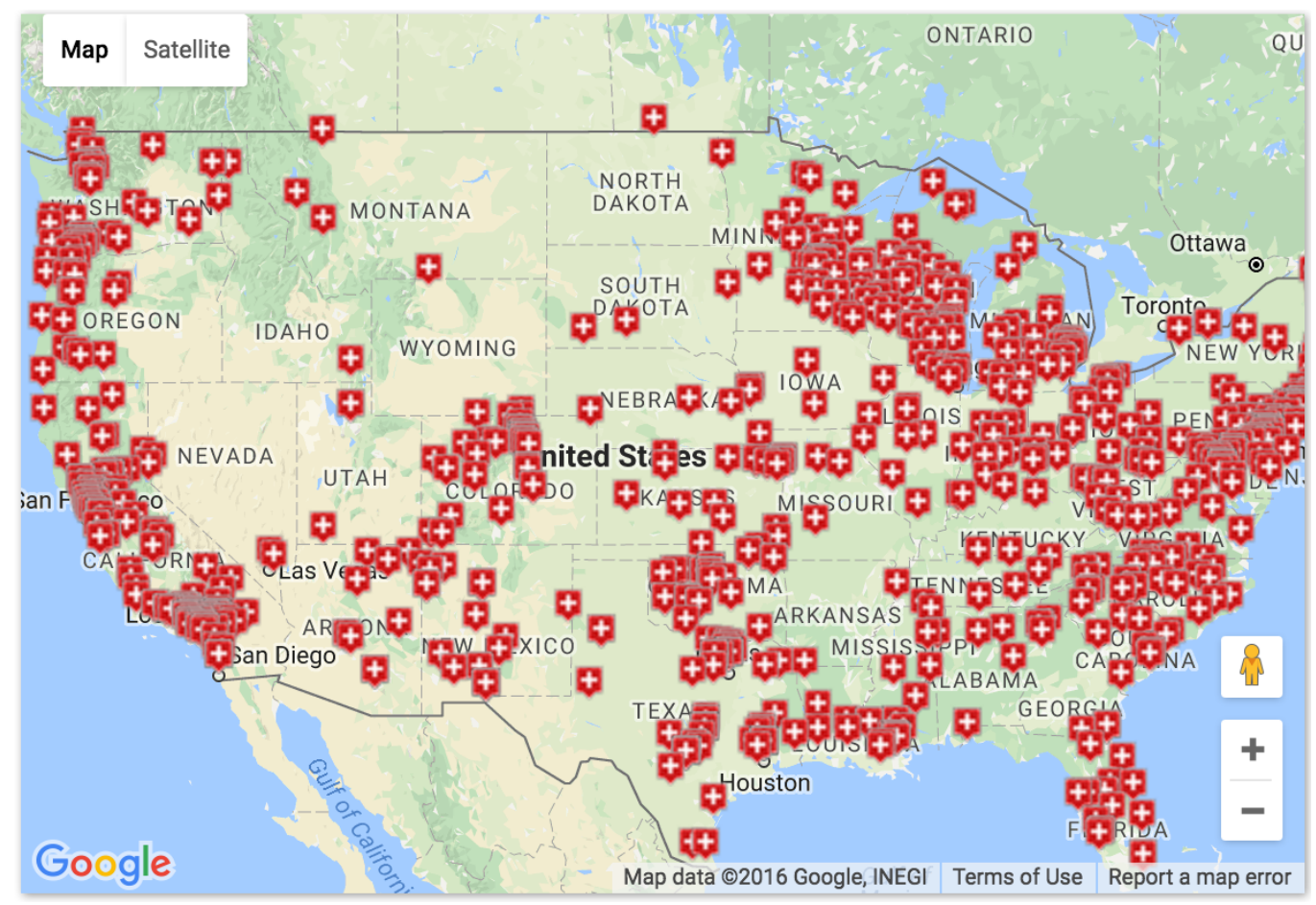


Figure 2: Two-period Hotelling Model

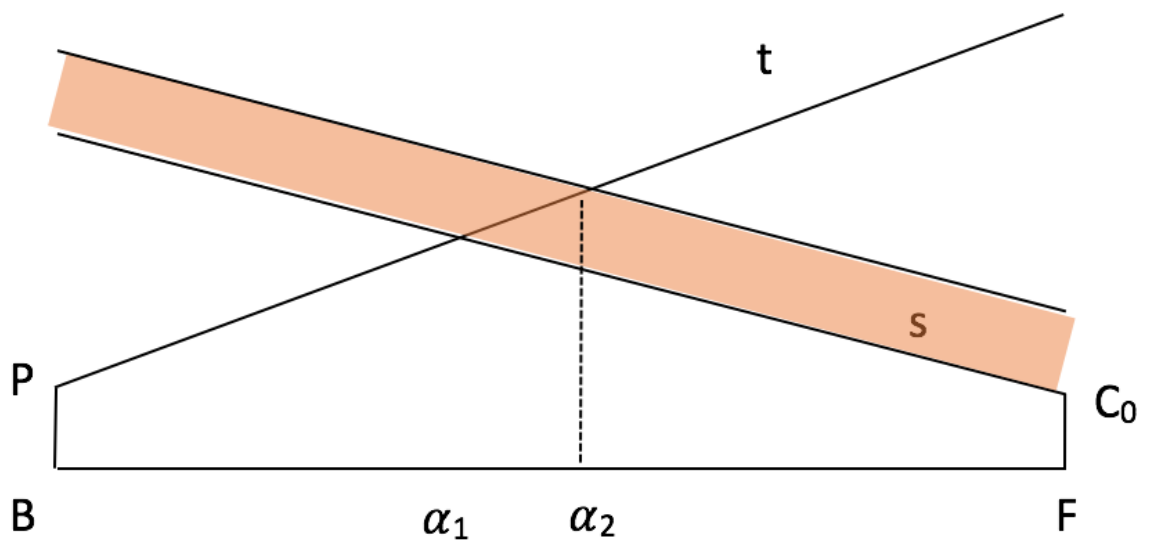

Period 2 
Figure 3: Equilibrium Price and Switching Cost

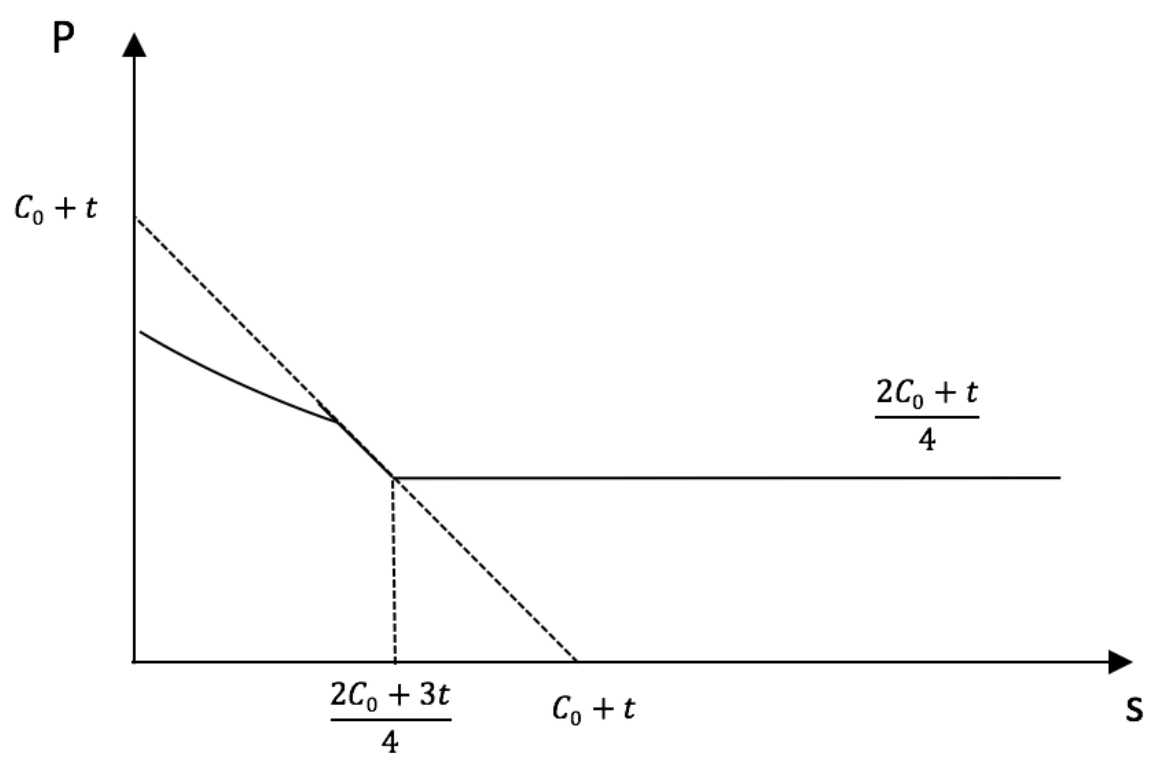


Figure 4: Nonparametric Survival Functions

Whether Consumers have Received Discharge Packages

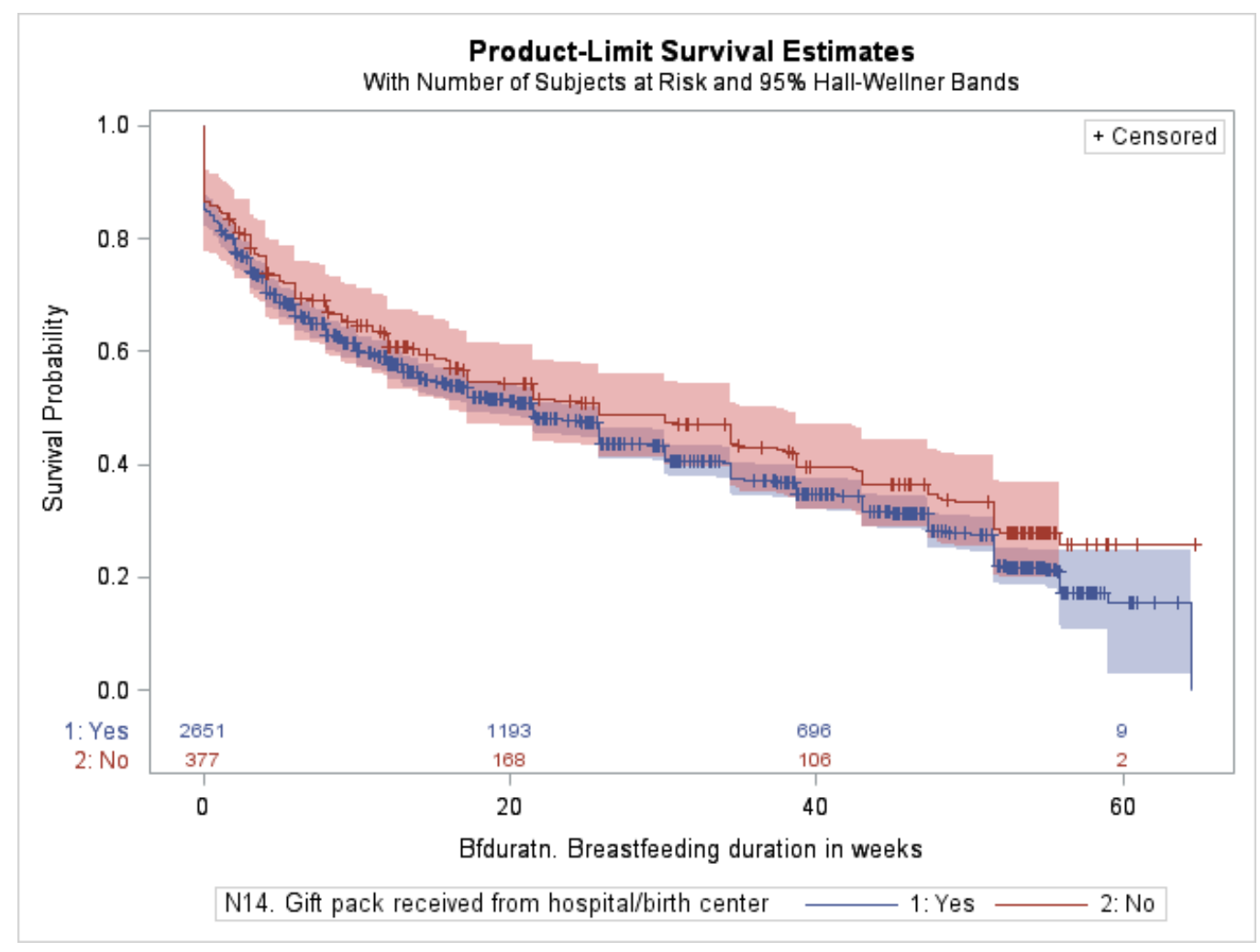


Figure 5: Nonparametric Survival Functions

Whether Free Infant Formula Gifts are in Discharge Packages

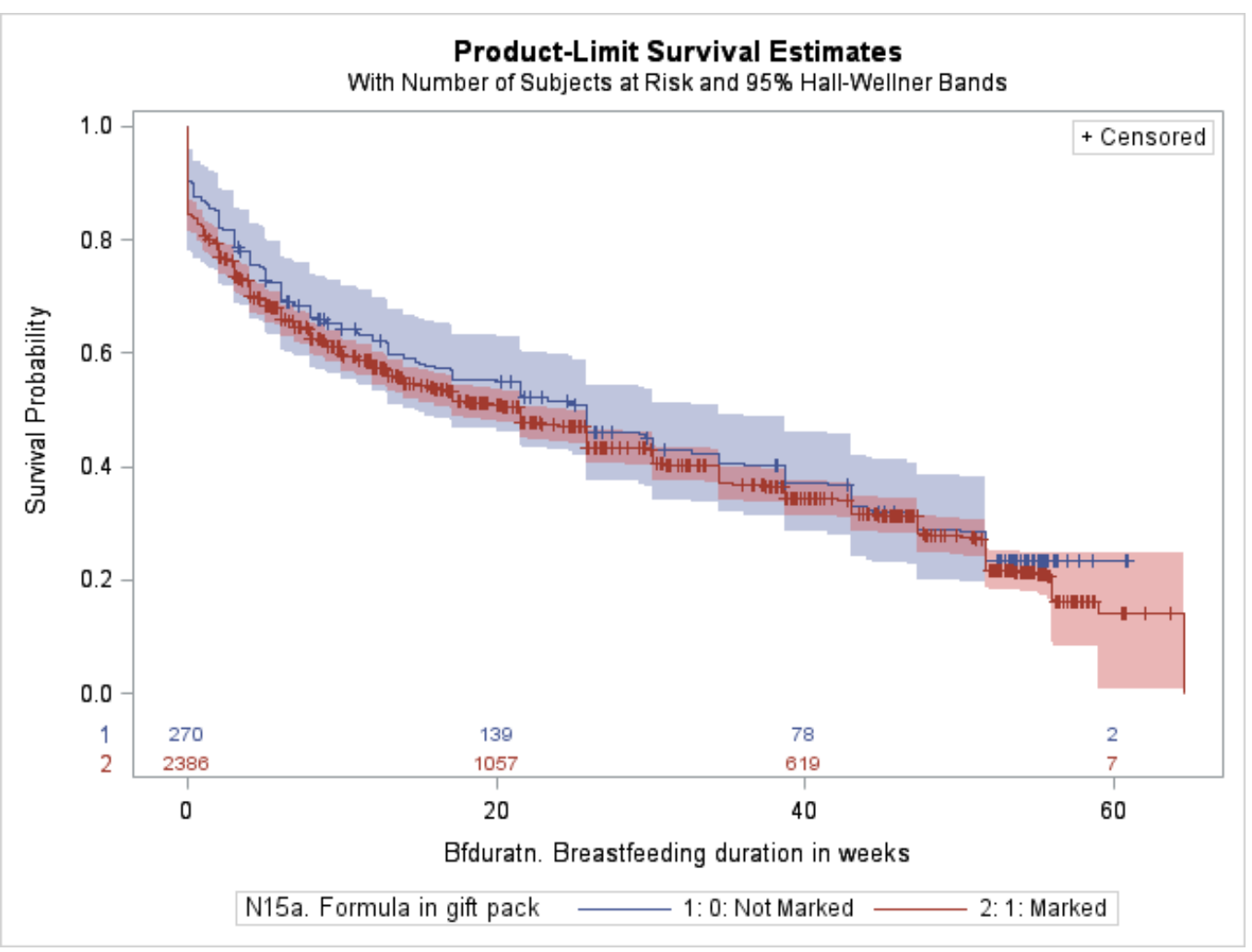


Figure 6: Realized and Planned Breastfeeding Durations

(a) Month 1 Postpartum

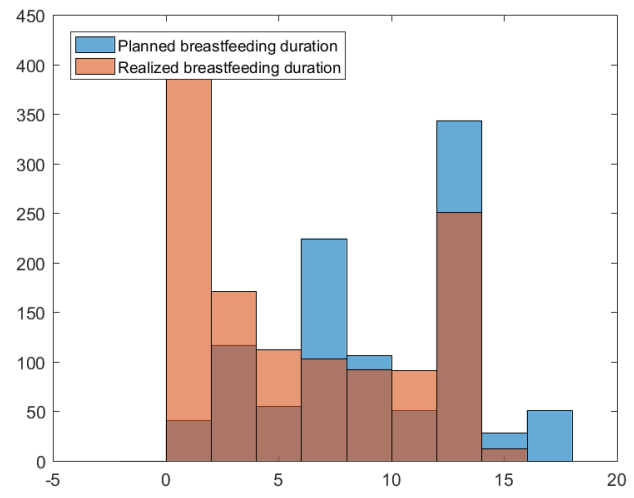

(c) Month 5 Postpartum

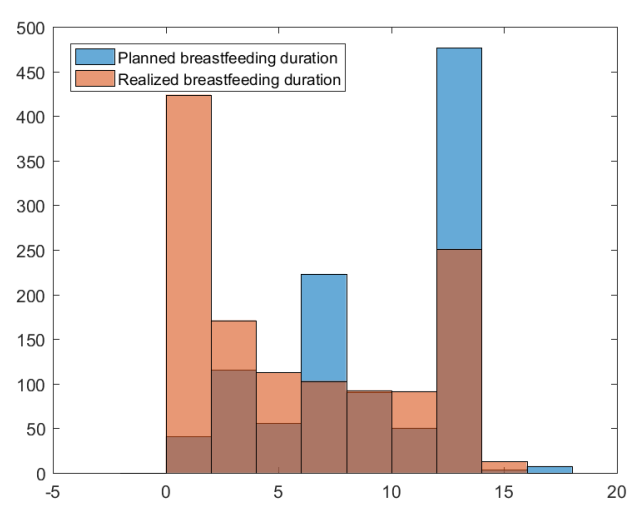

(b) Month 2 Postpartum

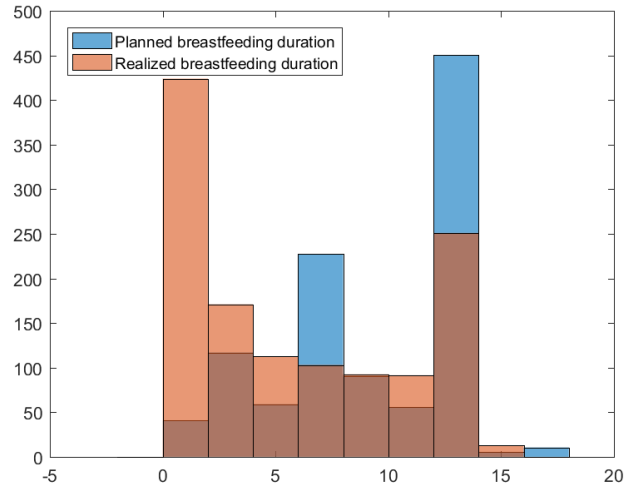

(d) Month 7 Postpartum

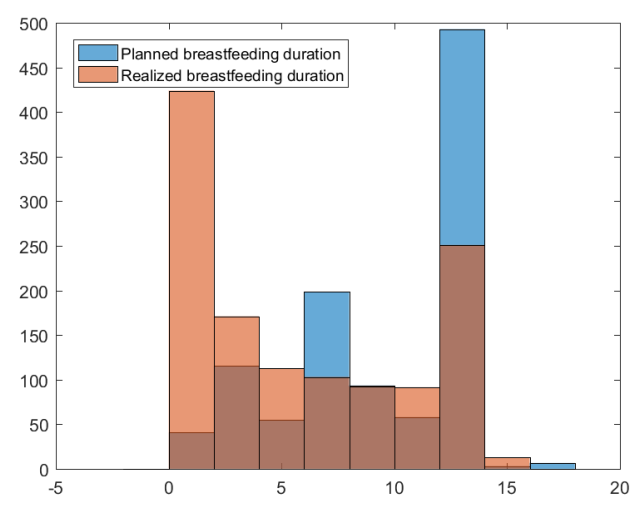


Figure 7: Infant Formula Price Timeline

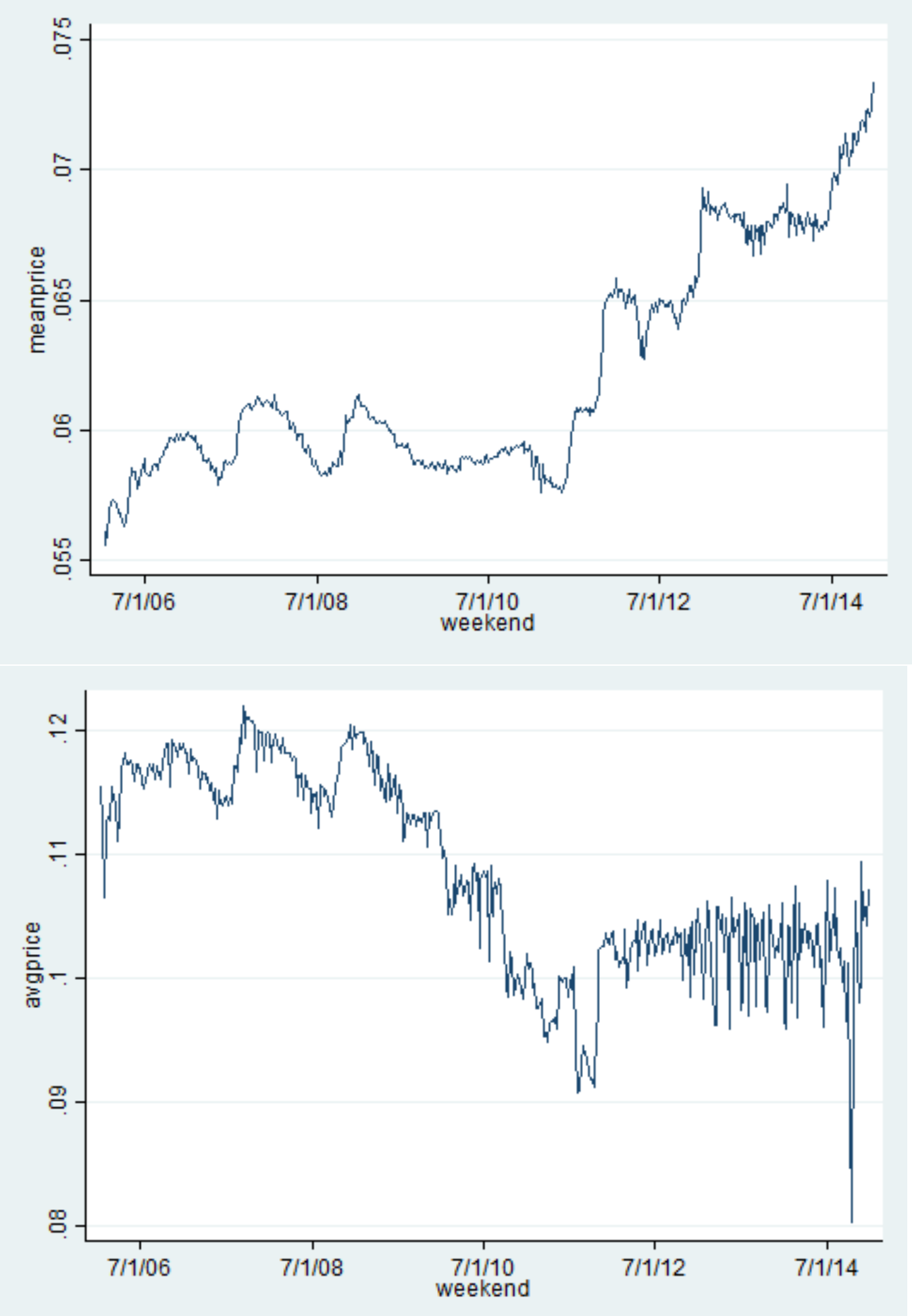


Figure 8: Data versus Model Simulation for Present-biased and Myopic Agents

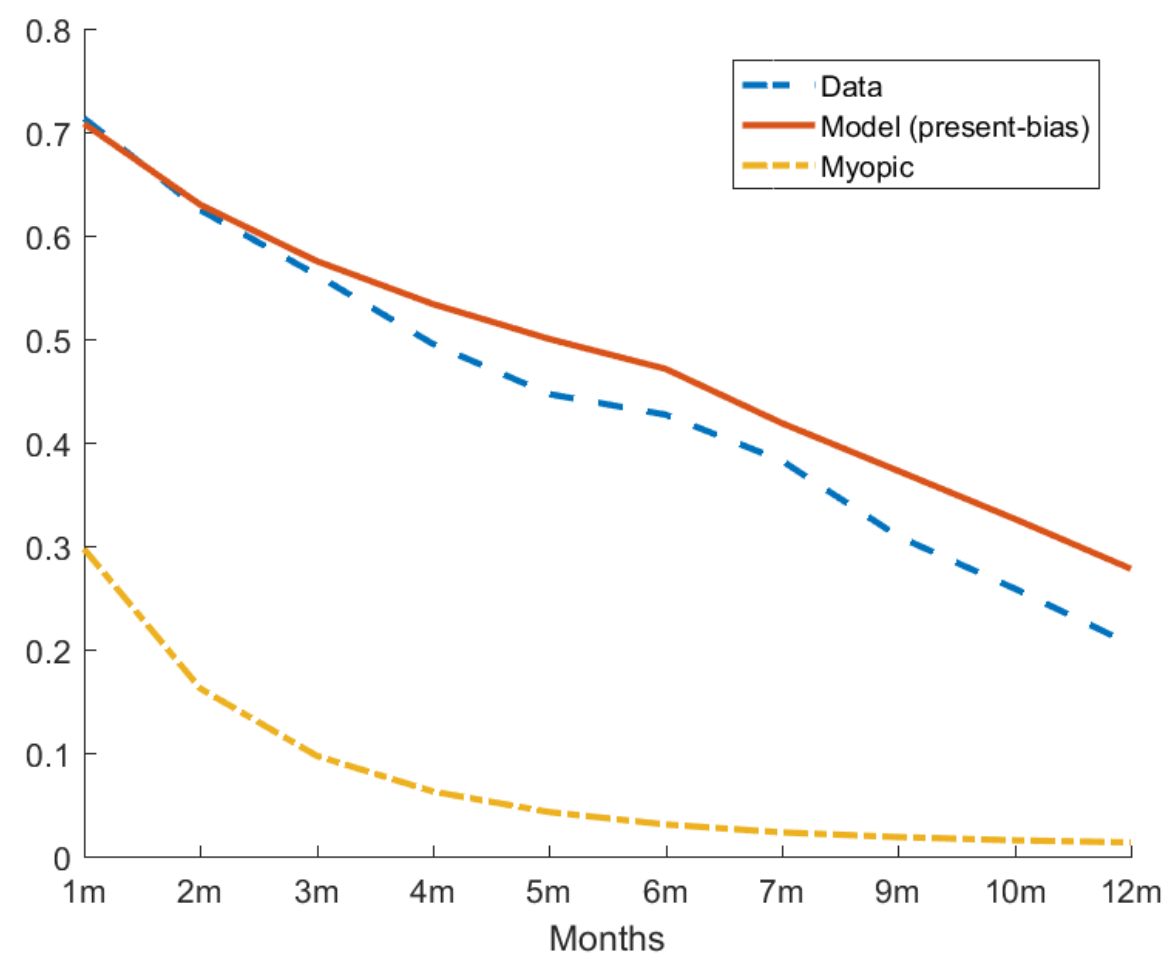


Figure 9: Breastfeeding Ratio Timeline

Contribution by State Dependence

(a) Present-Biased Preferences

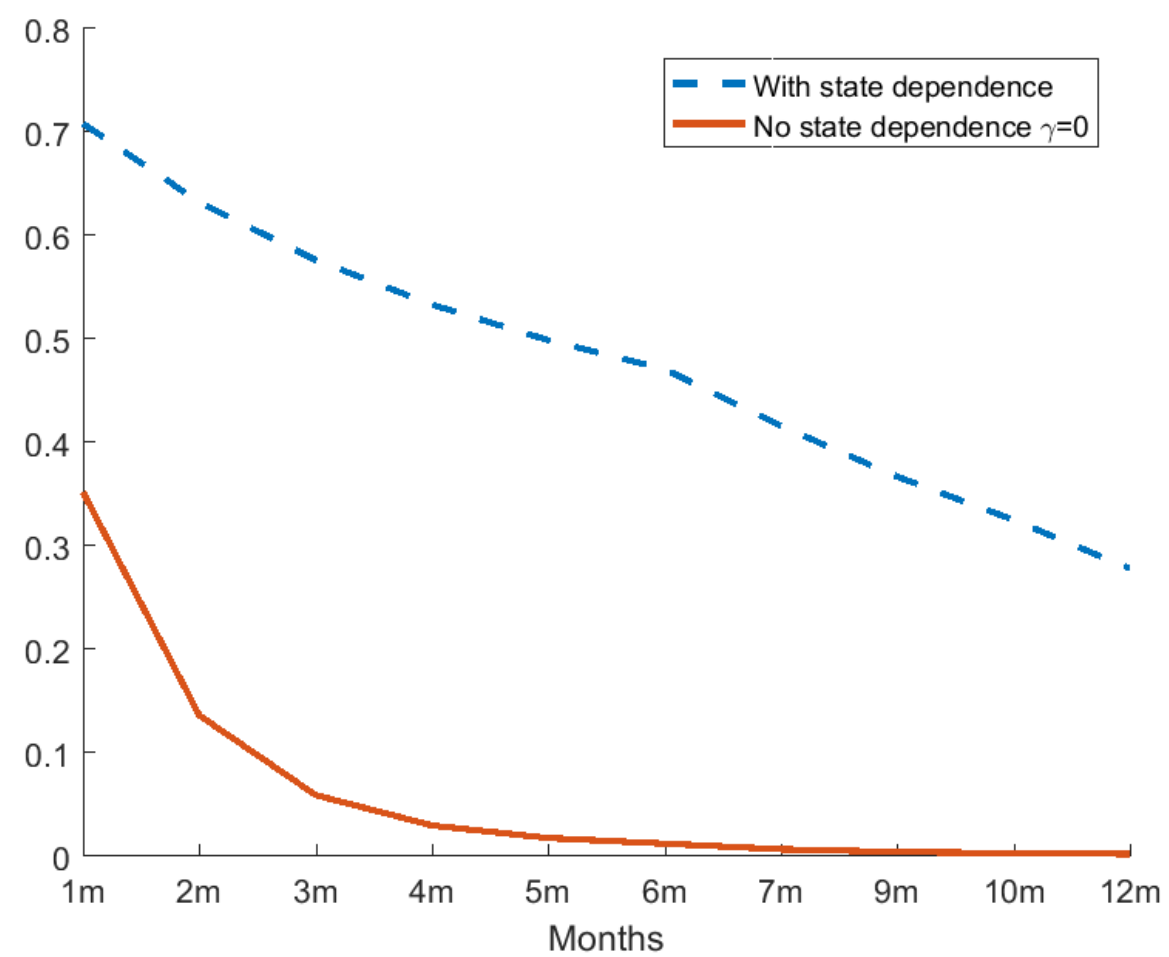

(b) Time-Consistent Preferences

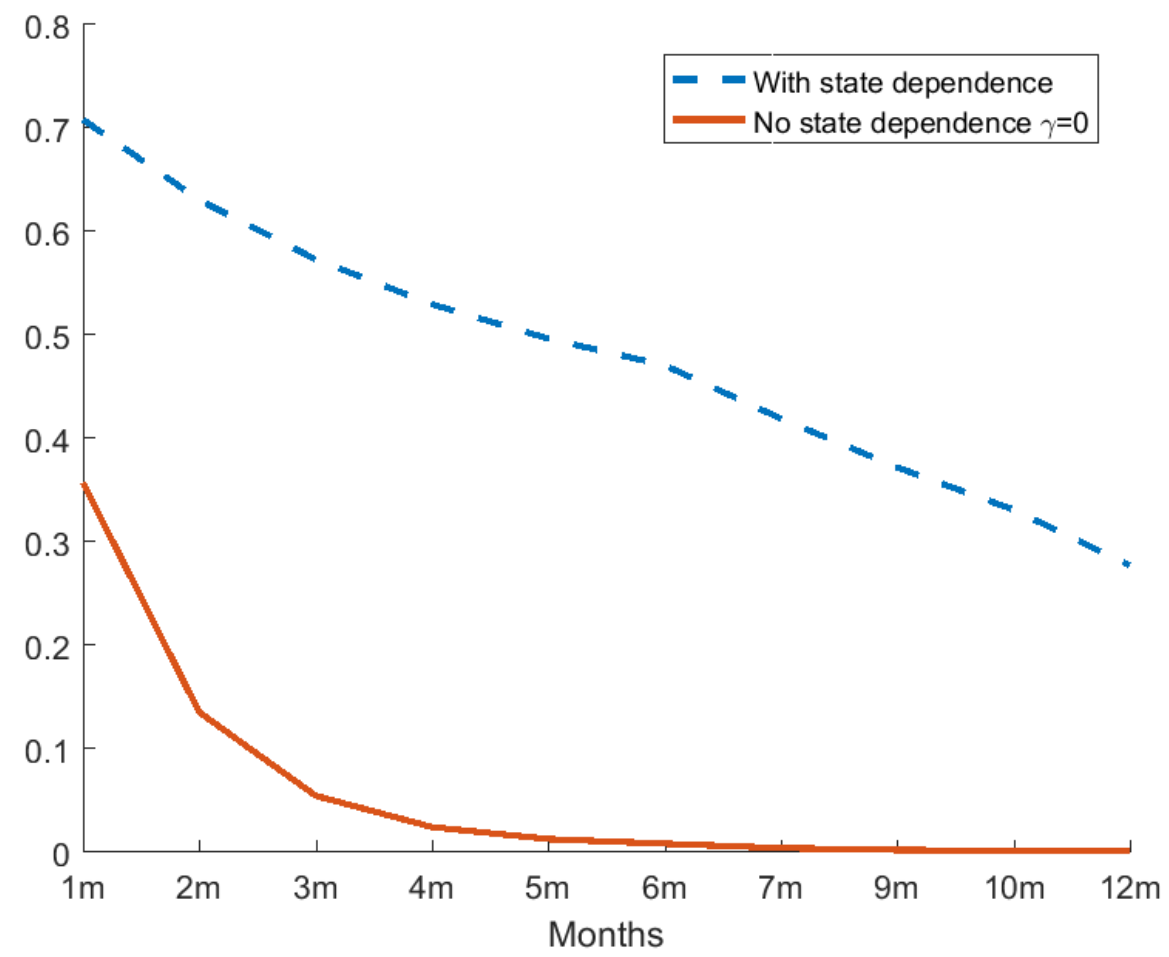


Figure 10: Breastfeeding Ratio Timeline

Contribution by Gift Packs

(a) Present-Biased Preferences

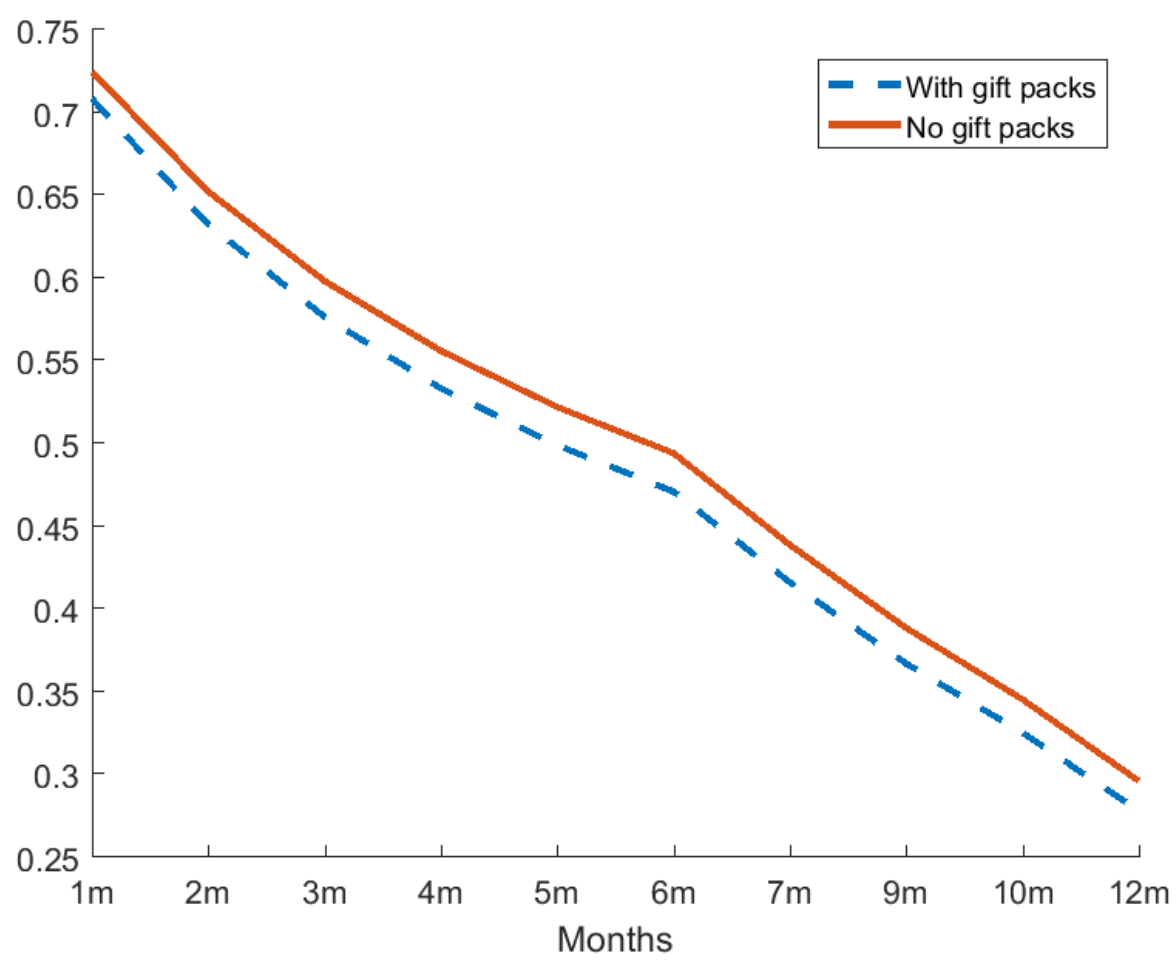

(b) Time-Consistent Preferences

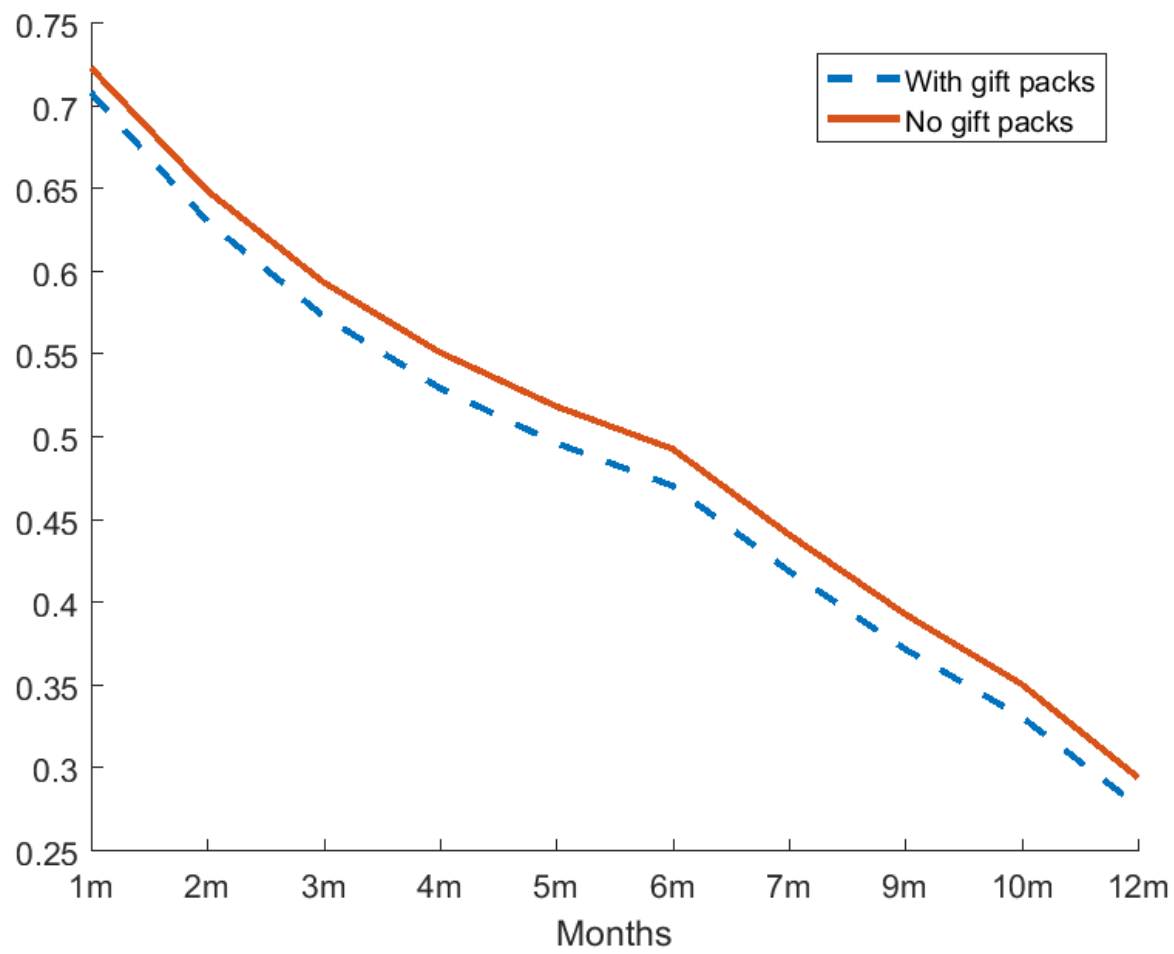


Figure 11: Breastfeeding Ratio Timeline

Contribution by State Dependence

(a) Present-Biased Preferences

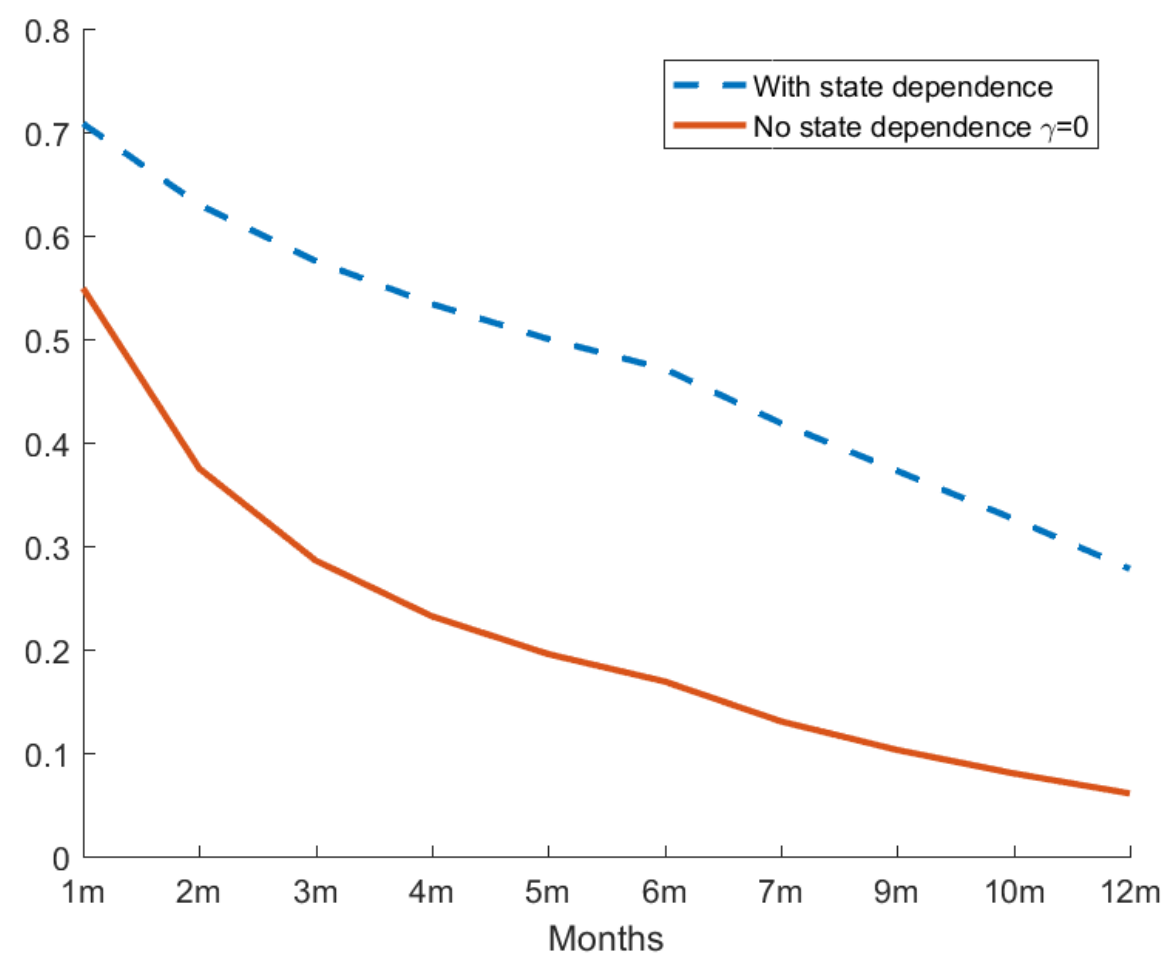

(b) Time-Consistent Preferences

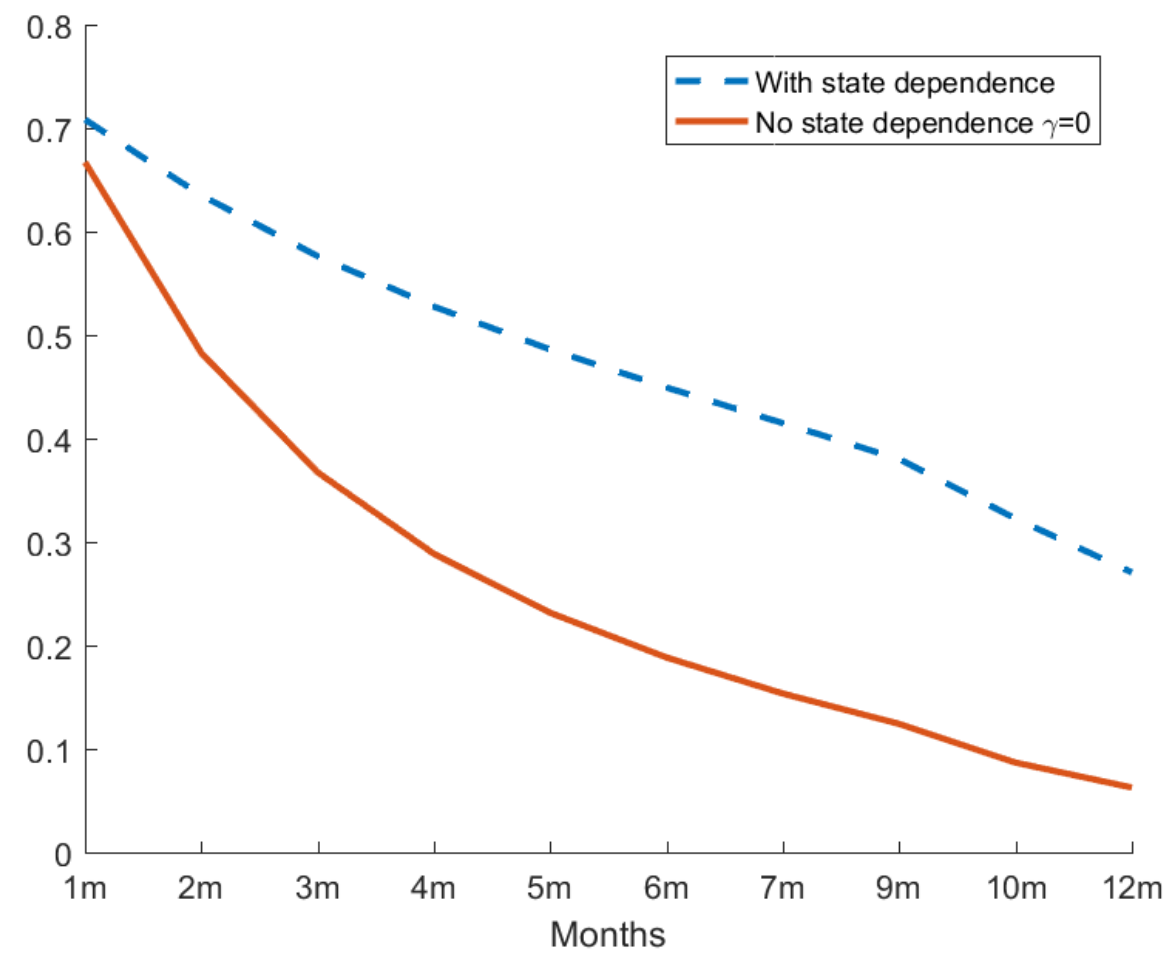


Figure 12: Breastfeeding Ratio Timeline

Contribution by Gift Packs

(a) Present-Biased Preferences

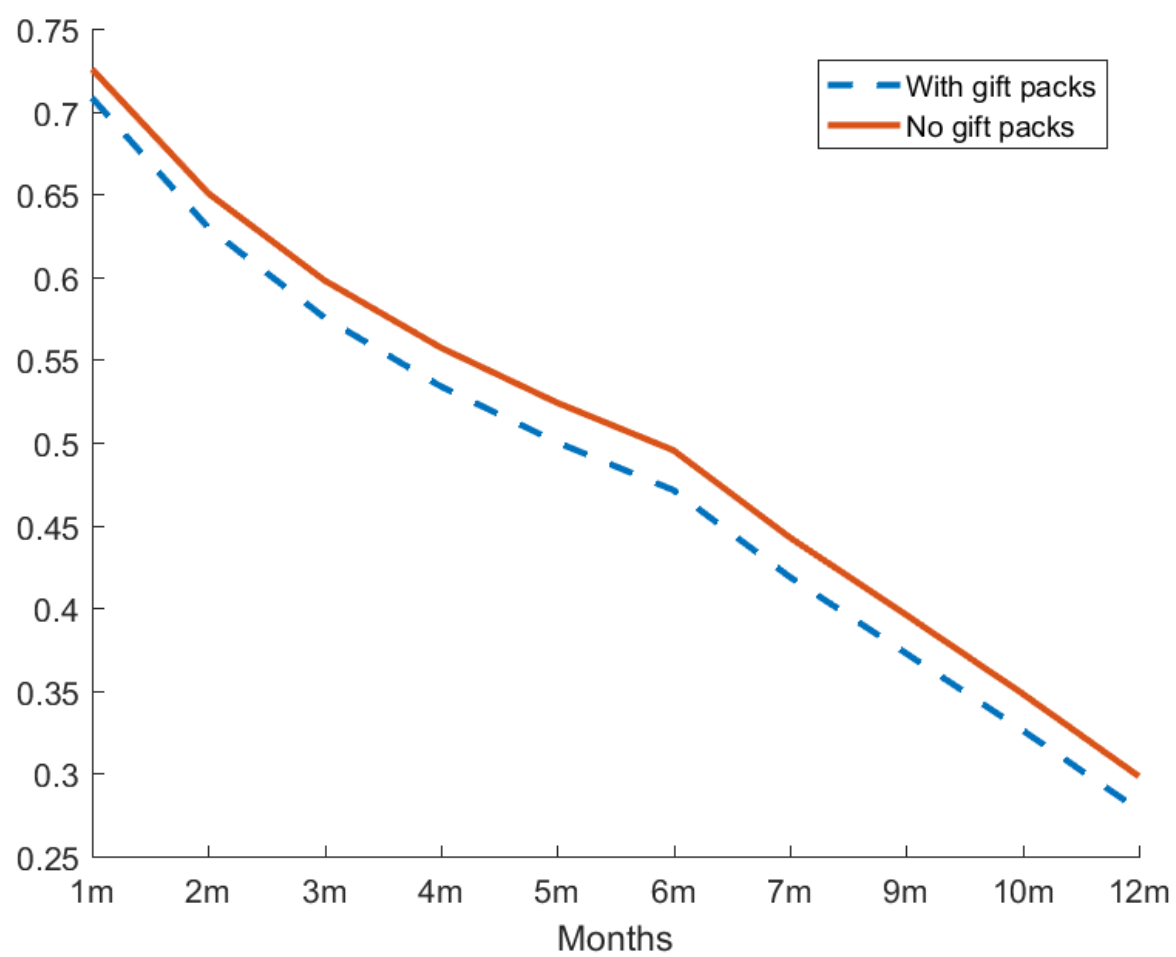

(b) Time-Consistent Preferences

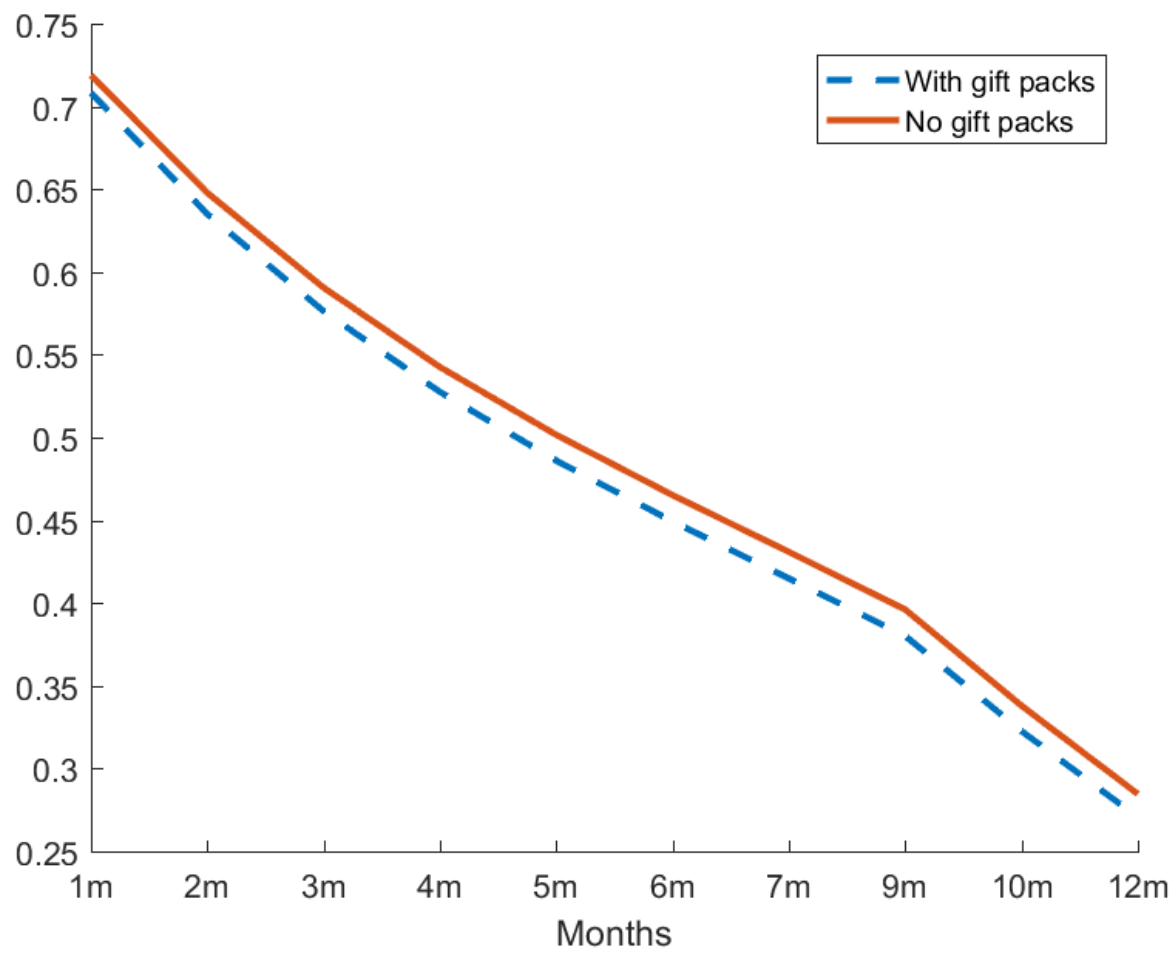


Figure 13: Switching Ratio from Breastfeeding to Formula Feeding

(a) All Hospitals Ban Free Bags

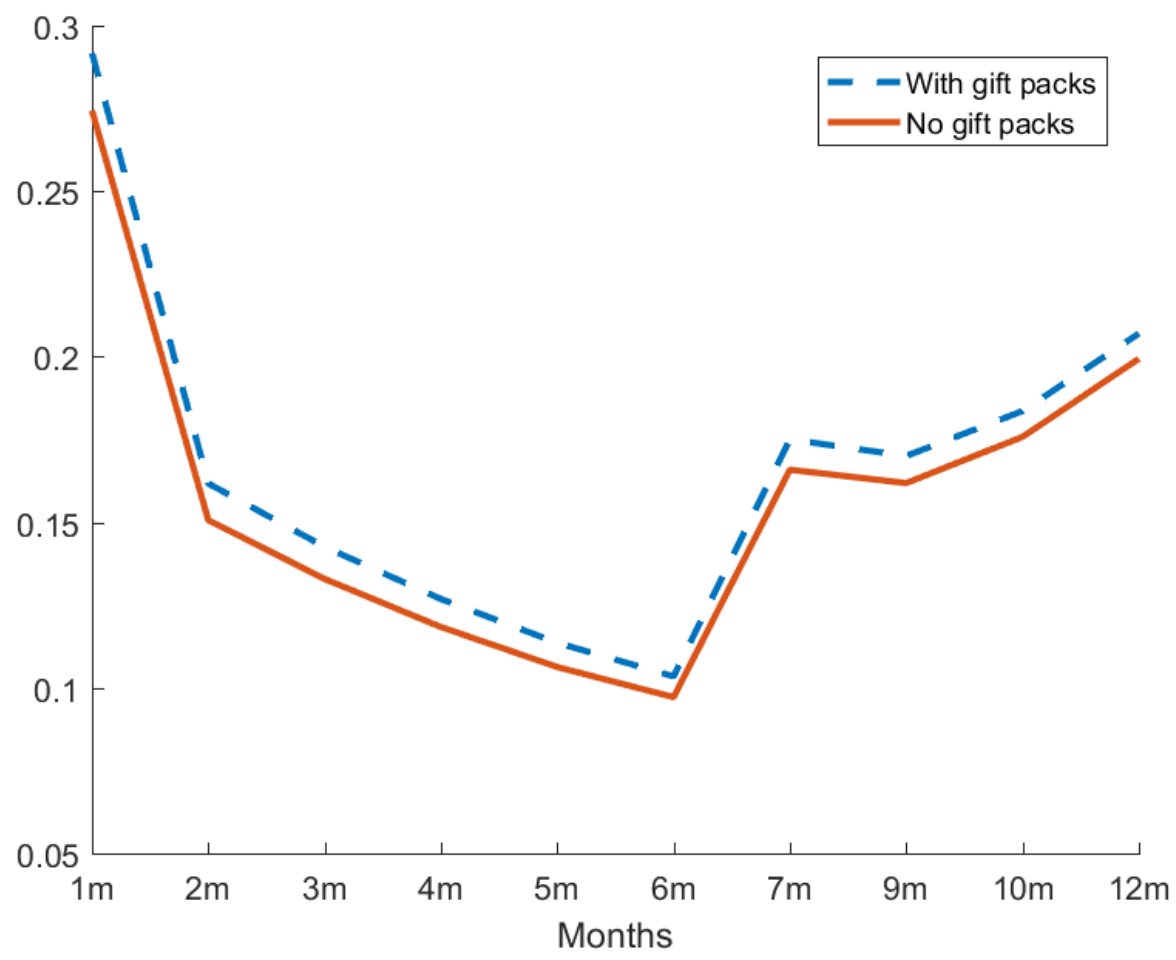

(b) No State Dependence

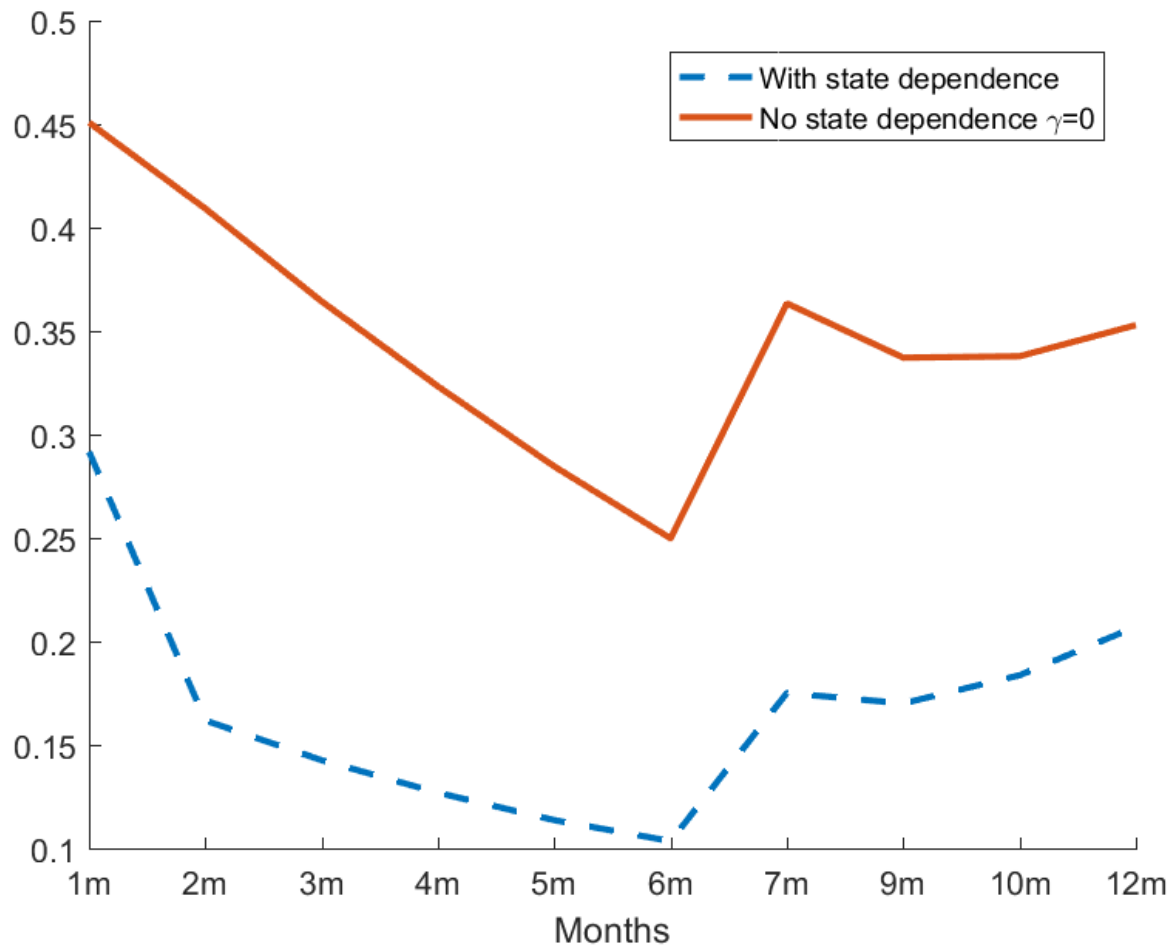


12.2 Tables 
Table 1: Infant Feeding Practices Study II Postnatal Questionnaire Topics and Month in Which Questions on Those Topics Were Administered

\begin{tabular}{|c|c|c|c|c|c|c|c|c|c|}
\hline Topics & & & & onth & $\mathrm{f} \mathrm{Qu}$ & stionr & aire & & \\
\hline & $2 \mathrm{~m}$ & $3 \mathrm{~m}$ & $4 \mathrm{~m}$ & $5 \mathrm{~m}$ & $6 \mathrm{~m}$ & $7 \mathrm{~m}$ & $9 \mathrm{~m}$ & $10 \mathrm{~m}$ & $12 \mathrm{~m}$ \\
\hline $\begin{array}{l}\text { Food frequency checklist, dietary } \\
\text { and herbal supplement intake }\end{array}$ & $\mathrm{X}$ & $\mathrm{X}$ & $\mathrm{X}$ & $\mathrm{X}$ & $\mathrm{X}$ & $\mathrm{X}$ & $\mathrm{X}$ & $\mathrm{X}$ & $\mathrm{X}$ \\
\hline $\begin{array}{l}\text { Edinburgh } \text { Postpartum } \\
\text { sion Scale }\end{array}$ & $\mathrm{X}$ & & & & & & & & \\
\hline $\begin{array}{l}\text { Breastfeeding and infant formula } \\
\text { feeding general information }\end{array}$ & $\overline{\mathrm{X}}$ & $\mathrm{X}$ & $\mathrm{X}$ & $\mathrm{X}$ & $\mathrm{X}$ & $\mathrm{X}$ & $\bar{X}$ & $\mathrm{X}$ & $\mathrm{X}$ \\
\hline Infant health problems & $\mathrm{X}$ & $\mathrm{X}$ & $\mathrm{X}$ & $\mathrm{X}$ & $\mathrm{X}$ & $\mathrm{X}$ & $\mathrm{X}$ & $\mathrm{X}$ & $\mathrm{X}$ \\
\hline Infant length and weight & & $\mathrm{X}$ & & $\mathrm{X}$ & & $\mathrm{X}$ & & & $\mathrm{X}$ \\
\hline $\begin{array}{l}\text { Use of antibiotics and other } \\
\text { prescription and nonprescription } \\
\text { medicines }\end{array}$ & $\mathrm{X}$ & $\mathrm{X}$ & $\mathrm{X}$ & $\mathrm{X}$ & $\mathrm{X}$ & $\mathrm{X}$ & $\mathrm{X}$ & $\mathrm{X}$ & $\mathrm{X}$ \\
\hline Stool characteristics & $\mathrm{X}$ & $\mathrm{X}$ & $\mathrm{X}$ & $\mathrm{X}$ & $\mathrm{X}$ & $\mathrm{X}$ & $\mathrm{X}$ & $\mathrm{X}$ & $\mathrm{X}$ \\
\hline $\begin{array}{l}\text { Stopped breastfeeding: age, } \\
\text { reasons, breastfeeding attitudes }\end{array}$ & $\mathrm{X}$ & $\mathrm{X}$ & $\mathrm{X}$ & $\mathrm{X}$ & $\mathrm{X}$ & $\mathrm{X}$ & $\mathrm{X}$ & $\mathrm{X}$ & $\mathrm{X}$ \\
\hline WIC participation & $\mathrm{X}$ & $\mathrm{X}$ & $\mathrm{X}$ & $\mathrm{X}$ & $\mathrm{X}$ & $\mathrm{X}$ & $\mathrm{X}$ & $\mathrm{X}$ & $\mathrm{X}$ \\
\hline $\begin{array}{l}\text { Breastfeeding and breast pumping } \\
\text { details }\end{array}$ & $\mathrm{X}$ & & & $\mathrm{X}$ & & $\mathrm{X}$ & & & \\
\hline $\begin{array}{l}\text { Mother's dietary changes because } \\
\text { of breastfeeding and reasons for } \\
\text { changes }\end{array}$ & $\mathrm{X}$ & & & $\mathrm{X}$ & & $\mathrm{X}$ & & & \\
\hline $\begin{array}{l}\text { Information sources about breast- } \\
\text { feeding, diet while breastfeeding, } \\
\text { and breast pumps }\end{array}$ & $\mathrm{X}$ & & & & & & & & \\
\hline Formula feeding details & $\mathrm{X}$ & & & $\mathrm{X}$ & & $\mathrm{X}$ & $\mathrm{X}$ & & \\
\hline Sleeping arrangements & & $\mathrm{X}$ & & & $\mathrm{X}$ & & $\mathrm{X}$ & & $\mathrm{X}$ \\
\hline $\begin{array}{l}\text { Employment status and } \\
\text { characteristics }\end{array}$ & & $\mathrm{X}$ & & & $\mathrm{X}$ & & $\mathrm{X}$ & & $\mathrm{X}$ \\
\hline Child care & & $\mathrm{X}$ & & & $\mathrm{X}$ & & $\mathrm{X}$ & & $\mathrm{X}$ \\
\hline $\begin{array}{l}\text { Mother's current health and } \\
\text { weight }\end{array}$ & & $\mathrm{X}$ & & & $\mathrm{X}$ & & $\mathrm{X}$ & & $\mathrm{X}$ \\
\hline $\begin{array}{l}\text { Mother's tobacco use and smoking } \\
\text { in home }\end{array}$ & & $\mathrm{X}$ & & & $\mathrm{X}$ & & $\mathrm{X}$ & & $\mathrm{X}$ \\
\hline $\begin{array}{l}\text { National Breastfeeding Awareness } \\
\text { Campaign evaluation questions }\end{array}$ & & $\mathrm{X}$ & & & & $\mathrm{X}$ & & & \\
\hline Food allergy & & & $\mathrm{X}$ & & & & $\mathrm{X}$ & & $\mathrm{X}$ \\
\hline Solid food feeding details & & & & $\mathrm{X}$ & $\mathrm{X}$ & $\mathrm{X}$ & $\mathrm{X}$ & $\mathrm{X}$ & $\mathrm{X}$ \\
\hline $\begin{array}{l}\text { Sources of information about } \\
\text { herbal products and general infant } \\
\text { feeding }\end{array}$ & & & $\mathrm{X}$ & & & & & $\mathrm{X}$ & \\
\hline
\end{tabular}


Table 2: Distribution of Select Characteristics Among Participants in IFPS and NSFG

\begin{tabular}{|c|c|c|}
\hline Characteristic & $\begin{array}{c}\text { Percentage of IFPS II sample } \\
\text { (mothers of infants born in } 2005) \dagger\end{array}$ & $\begin{array}{c}\text { Percentage of NSFG sample* } \\
\text { (mothers of infants born in 1998-2000) }\end{array}$ \\
\hline \multicolumn{3}{|c|}{ ) } \\
\hline $18-24 \ddagger$ & 23.3 & 32.6 \\
\hline $25-34$ & 61.4 & 54.9 \\
\hline $35-43$ & 15.3 & 12.4 \\
\hline \multicolumn{3}{|l|}{ Marital status } \\
\hline Married or cohabiting $\S$ & 79.1 & 79.5 \\
\hline Other & 20.9 & 20.5 \\
\hline \multicolumn{3}{|l|}{ Education } \\
\hline HS or less $\ddagger$ & 21.0 & 47.5 \\
\hline Some college & 40.2 & 27.8 \\
\hline College graduate & 38.8 & 24.7 \\
\hline \multicolumn{3}{|l|}{ Income ( $\%$ of poverty) } \\
\hline$<185 \% \ddagger$ & 41.9 & 45.2 \\
\hline $185-349 \%$ & 35.8 & 27.4 \\
\hline$>350 \%$ & 22.3 & 27.4 \\
\hline \multicolumn{3}{|c|}{ Employment status (prenatal) } \\
\hline Employed $\ddagger$ & 66.3 & 61.2 \\
\hline Not employed & 33.7 & 38.8 \\
\hline \multicolumn{3}{|l|}{ Race/ethnicity } \\
\hline Whitef & 84.4 & 61.5 \\
\hline Black & 4.9 & 14.1 \\
\hline Hispanic & 6.2 & 18.9 \\
\hline Other & 4.6 & 5.4 \\
\hline \multicolumn{3}{|l|}{ Region } \\
\hline West & 20.1 & 24.5 \\
\hline Midwest & 30.0 & 23.7 \\
\hline South $\ddagger$ & 32.6 & 40.3 \\
\hline Northeast & 17.3 & 11.5 \\
\hline \multicolumn{3}{|l|}{ Prenatal smoking } \\
\hline Yes $\ddagger$ & 9.9 & 12.0 \\
\hline No & 90.1 & 88.0 \\
\hline \multicolumn{3}{|l|}{ Prenatal care } \\
\hline$<13$ weeks $\ddagger$ & 88.6 & 91.9 \\
\hline $13-21$ weeks & 6.9 & 5.8 \\
\hline$\geq 22$ wks/never & 4.5 & 2.3 \\
\hline \multicolumn{3}{|l|}{ Total maternity leave taken } \\
\hline$\leq 6$ weeks $\ddagger$ & 21.0 & 38.1 \\
\hline$>6$ weeks & 79.0 & 61.9 \\
\hline Obs. & 3,033 & 1,415 \\
\hline
\end{tabular}

* The NSFG sample was limited to most recent singleton live births to women 18-44 years old at delivery. Weighted percentages are reported.

† Sample sizes vary slightly because of missing data on some variables.

$\ddagger$ T-tests were conducted to evaluate the differences between NSFG and IFPS characteristics, which required that all variables be dichotomized. Multi-level variables were categorized by keeping one category and collapsing all others. The $\dagger$ for multi-level variables indicates the category that was kept and that it was significantly different across the two samples at $\mathrm{p}<.05$. For dichotomous variables, the $\dagger$ indicates that the variable was significantly different across samples.

$\S$ Category marked was kept and was not significantly different across the two samples. 
Table 3: Summary Statistics - Grouped by Receiving Gift Bags or Not

\begin{tabular}{|c|c|c|c|c|}
\hline & $\begin{array}{l}\text { Gift bag } \\
\text { received }\end{array}$ & $\begin{array}{c}\text { Gift bag } \\
\text { not received }\end{array}$ & $\begin{array}{c}\text { Mean } \\
\text { difference }\end{array}$ & $\begin{array}{c}\mathrm{P} \text { Value } \\
H_{0}: \text { difference }=0\end{array}$ \\
\hline & mean & mean & & \\
\hline Income & $\$ 35,000-\$ 39,999$ & $\$ 35,000-\$ 39,999$ & -0.10 & 0.75 \\
\hline Household size & 3.28 & 3.54 & -0.26 & 0.00 \\
\hline Breastfeeding duration (Weeks) & $\begin{array}{c}23.04 \\
\text { percentage }\end{array}$ & $\begin{array}{c}25.22 \\
\text { percentage }\end{array}$ & -2.18 & 0.08 \\
\hline Married & 79.73 & 83.56 & -0.04 & 0.12 \\
\hline White & 87.01 & 91.26 & -0.04 & 0.07 \\
\hline Education & & & -0.00 & 0.92 \\
\hline HS or less & 20.9 & 17.79 & & \\
\hline Some college & 39.19 & 44.97 & & \\
\hline College graduate & 39.91 & 37.25 & & \\
\hline Employment & & & -0.07 & 0.06 \\
\hline Employed & 54.85 & 47.99 & & \\
\hline Unemployed & 41.13 & 48.32 & & \\
\hline Not in labor force & 4.02 & 3.09 & & \\
\hline Age of mother (years) & & & -0.71 & 0.18 \\
\hline $18-24$ & 20.09 & 16.11 & & \\
\hline $25-34$ & 63.34 & 64.77 & & \\
\hline $35-47$ & 16.57 & 19.13 & & \\
\hline Best way to feed a baby & & & -0.08 & 0.28 \\
\hline Breastfeeding & 69.93 & 68.12 & & \\
\hline Both breastfeeding and formula feeding & 10.88 & 9.40 & & \\
\hline Both equally good ways to feed a baby & 16.98 & 19.46 & & \\
\hline Formula feeding & 2.21 & 3.02 & & \\
\hline Infant formula is as good as breast milk & & & 0.02 & 0.81 \\
\hline Strongly disagree & 27.22 & 33.22 & & \\
\hline Somewhat disagree & 34.04 & 28.19 & & \\
\hline Neither agree or disagree & 11.92 & 11.07 & & \\
\hline Somewhat agree & 20.00 & 17.11 & & \\
\hline Strongly agree & 6.82 & 10.40 & & \\
\hline Mother was ever breastfed & & & -0.04 & 0.28 \\
\hline Yes & 47.76 & 44.97 & & \\
\hline No & 45.80 & 47.32 & & \\
\hline Not sure/Don't know & 6.44 & 7.72 & & \\
\hline Price & 47.35 & 47.63 & -0.28 & 0.89 \\
\hline Obs. & 2,215 & 298 & & \\
\hline
\end{tabular}


Table 4: Cox Regression Analysis of Breastfeeding Duration*

\begin{tabular}{lccc}
\hline & Coefficient & Hazard Ratio & P Value \\
\cline { 2 - 4 } Gift pack received from hospital/birth center & 0.228 & 1.256 & 0.0114 \\
Child enrolled in WIC in past month & 0.542 & 1.600 & $<0.0001$ \\
Income & 0.018 & 1.019 & 0.0047 \\
White or Asian & -0.158 & 0.854 & 0.0660 \\
Married & -0.320 & 0.726 & $<0.0001$ \\
Employed by others & 0.324 & 1.383 & $<0.0001$ \\
Not in labor force & 0.306 & 1.359 & 0.0381 \\
High school graduate and below & 0.688 & 1.991 & $<0.0001$ \\
Some college & 0.346 & 1.414 & 0.0006 \\
Mother's age & -0.020 & 0.980 & 0.0005 \\
Mother returned to work & 0.208 & 1.231 & 0.0009 \\
Age of infant (in months) & 0.002 & 1.002 & 0.7723 \\
\hline
\end{tabular}

* The baseline refers to mothers who are black or Hispanic, not married, full time homemaker and college graduates and above.

Table 5: Demand Estimation

\begin{tabular}{lcccccc}
\hline & & \multicolumn{2}{c}{$(1)$} & & \multicolumn{2}{c}{$(2)$} \\
& & \multicolumn{2}{c}{ Present-Biased } & & Time Consistent \\
\cline { 3 - 4 } & Parameters & Estimate & s.e. & & Estimate & s.e. \\
\hline Present-bias discount factor & $\beta$ & 0.1963 & 0.0336 & & 1 & 0 \\
Long term discount factor & $\delta$ & 0.9298 & 0.0296 & & 0.3926 & 0.0559 \\
Breastfeeding at least six months & $\sigma_{1}$ & 6.1152 & 2.4786 & & 7.8551 & 1.8971 \\
State dependence & $\gamma$ & 0.8162 & 0.1206 & & 1.1243 & 0.1042 \\
Gift packs & $\phi$ & 0.0599 & 0.0517 & & 0.0722 & 0.0654 \\
\hline
\end{tabular}


Table 6: Demand Estimation*

\begin{tabular}{|c|c|c|c|c|}
\hline \multirow[b]{2}{*}{ Parameters } & \multicolumn{2}{|c|}{$\begin{array}{c}(1) \\
\text { Present-Biased }\end{array}$} & \multicolumn{2}{|c|}{$\begin{array}{c}(2) \\
\text { Time Consistent }\end{array}$} \\
\hline & Estimate & s.e. & Estimate & s.e. \\
\hline Price & -0.0163 & 0.0026 & -0.0184 & 0.0022 \\
\hline Constant & -3.4581 & 0.2481 & -3.4419 & 0.3164 \\
\hline WIC participation & 0.4165 & 0.0855 & 0.4428 & 0.0908 \\
\hline Return to Work & -0.0572 & 0.0461 & -0.0924 & 0.0537 \\
\hline \multicolumn{5}{|l|}{ Income } \\
\hline Middle class & -0.0304 & 0.0443 & -0.0484 & 0.0573 \\
\hline High class & -0.2152 & 0.0776 & -0.2964 & 0.096 \\
\hline Married & 0.1571 & 0.0472 & 0.2188 & 0.0595 \\
\hline \multicolumn{5}{|l|}{ Education } \\
\hline Some College & 0.0665 & 0.0448 & 0.0974 & 0.0583 \\
\hline College graduates and above & 0.2221 & 0.0556 & 0.2806 & 0.0679 \\
\hline Employed & -0.1004 & 0.0381 & -0.1189 & 0.0473 \\
\hline White & -0.0203 & 0.0487 & 0.0023 & 0.0631 \\
\hline \multicolumn{5}{|l|}{ Age of mother (in years) } \\
\hline $25-34$ & 0.2261 & 0.0512 & 0.3035 & 0.0628 \\
\hline $35-47$ & 0.2507 & 0.0635 & 0.3383 & 0.0774 \\
\hline \multicolumn{5}{|l|}{ Best way to feed a baby } \\
\hline Breastfeeding & 1.0142 & 0.2159 & 1.6433 & 0.2964 \\
\hline Both breastfeeding and formula feeding & 0.7908 & 0.205 & 1.3227 & 0.294 \\
\hline Both equally good ways to feed a baby & 0.553 & 0.1922 & 1.0634 & 0.2861 \\
\hline \multicolumn{5}{|l|}{ Infant formula is as good as breast milk } \\
\hline Strongly disagree & 0.6918 & 0.1079 & 0.8979 & 0.1254 \\
\hline Somewhat disagree & 0.4693 & 0.0907 & 0.6259 & 0.1129 \\
\hline neither agree or disagree & 0.3345 & 0.089 & 0.4537 & 0.1165 \\
\hline Somewhat agree & 0.2091 & 0.0787 & 0.2884 & 0.107 \\
\hline Mother was ever breastfed & 0.1489 & 0.0359 & 0.1823 & 0.044 \\
\hline Male infant & -0.0185 & 0.0321 & -0.0314 & 0.041 \\
\hline Age of Infant & 0.1492 & 0.0282 & 0.0279 & 0.0181 \\
\hline
\end{tabular}

* The baseline group refers to mothers with annual income below $\$ 1,5000$, high school and below education, ages falling in the range of 18-24 years old, opining that infant formula is the best way to feed a baby and infant formula is as good as breast milk strongly. 
Table 7: Attrition Equation*

\begin{tabular}{lcc}
\hline Parameters & Estimate & s.e. \\
\hline Household size & -0.0674 & 0.0077 \\
Income & & \\
$\quad$ Middle class & -0.0043 & 0.0233 \\
$\quad$ High class & -0.0381 & 0.0425 \\
Married & 0.2545 & 0.0249 \\
Education & & \\
$\quad$ Some College & -0.0322 & 0.0251 \\
College graduates and above & 0.2596 & 0.0291 \\
Employed & -0.0025 & 0.0198 \\
White & 0.152 & 0.0272 \\
Age of mother (in years) & & \\
25-34 & 0.3032 & 0.0249 \\
35-47 & 0.4838 & 0.0334 \\
Best way to feed a baby & & \\
Breastfeeding & 0.0757 & 0.066 \\
Both breastfeeding and formula feeding & -0.0426 & 0.0689 \\
Both equally good ways to feed a baby & 0.0895 & 0.0646 \\
Infant formula is as good as breast milk & & \\
$\quad$ Strongly disagree & -0.1222 & 0.0463 \\
Somewhat disagree & -0.0633 & 0.0443 \\
neither agree or disagree & -0.1697 & 0.0468 \\
Somewhat agree & -0.059 & 0.0433 \\
Age of infant & -0.0732 & 0.0029 \\
Constant & 0.6405 & 0.0777 \\
\hline
\end{tabular}

* The baseline group refers to mothers with annual income below $\$ 1,5000$, high school and below education, ages falling in the range of 18-24 years old, opining that infant formula is the best way to feed a baby and infant formula is as good as breast milk strongly. 
Table 8: Breastfeeding Ratio Timeline - Contribution by Gift Packs

\begin{tabular}{lccc}
\hline & \multicolumn{3}{c}{ Breastfeeding Ratio } \\
\hline \multirow{3}{*}{ Observed } & month 1 & month 6 & month 12 \\
\cline { 2 - 4 } Counterfactual (Present-biased) & $70.83 \%$ & $47.15 \%$ & $27.82 \%$ \\
Counterfactual (Time-consistent) & $71.89 \%$ & $49.93 \%$ & $30.19 \%$ \\
\hline
\end{tabular}

Table 9: Breastfeeding Ratio Timeline - Contribution by State Dependence

\begin{tabular}{lccc}
\hline & \multicolumn{3}{c}{ Breastfeeding Ratio } \\
\hline \multirow{2}{*}{ Observed } & month 1 & month 6 & month 12 \\
\cline { 2 - 4 } Counterfactual (present-biased) & $50.83 \%$ & $47.15 \%$ & $27.82 \%$ \\
Counterfactual (time-consistent) & $66.72 \%$ & $18.82 \%$ & $6.07 \%$ \\
\hline
\end{tabular}




\section{Bibliography}

[1] Ackerberg, D. (2003). Advertising, learning, and consumer choice in experience good markets: an empirical examination. International Economic Review, 44(3):1007-1040.

[2] Arellano, M. and Carrasco, R. (2003). Binary choice panel data models with predetermined variables. Journal of Econometrics, 115(1):125-157.

[3] Beggs, A. and Klemperer, P. (1992). Multi-period competition with switching costs. Econometrica, 60(3):651-66.

[4] Biglaiser, G., Crmer, J., and Dobos, G. (2014). Heterogenous switching costs. CEPR Discussion Papers 9809, C.E.P.R. Discussion Papers.

[5] Cabral, L. (2012). Switching costs and equilibrium prices. CEPR Discussion Papers 8970, C.E.P.R. Discussion Papers.

[6] Cabral, L. (2016). Dynamic pricing in customer markets with switching costs. Review of Economic Dynamics, 20:43-62.

[7] Carranza, J. E. (2010). Product innovation and adoption in market equilibrium: The case of digital cameras. International Journal of Industrial Organization, 28(6):604-618. 
[8] Chernozhukov, V., Fernndez?Val, I., Hahn, J., and Newey, W. (2013). Average and quantile effects in nonseparable panel models. Econometrica, 81(2):535-580.

[9] Chintagunta, P., Kyriazidou, E., and Perktold, J. (2001). Panel data analysis of household brand choices. Journal of Econometrics, 103(1-2):111-153.

[10] Crawford, G. and Shum, M. (2005). Uncertainty and learning in pharmaceutical demand. Econometrica, 73(4):1137-1173.

[11] Doganoglu, T. (2010). Switching costs, experience goods and dynamic price competition. Quantitative Marketing and Economics (QME), 8(2):167-205.

[12] Dub, J.-P., Hitsch, G. J., and Rossi, P. (2009a). Do switching costs make markets less competitive? Journal of Marketing Research, 46(4).

[13] Dub, J.-P., Hitsch, G. J., and Rossi, P. (2009b). State dependence and alternative explanations for consumer inertia. NBER Working Papers 14912, National Bureau of Economic Research, Inc.

[14] Erdem, T. (1996). A dynamic analysis of market structure based on panel data. Marketing Science, 15(4):359-378.

[15] Erdem, T., Keane, M., nc, T., and Strebel, J. (2005). Learning about computers: An analysis of information search and technology choice. Quantitative Marketing and Economics (QME), 3(3):207-247.

[16] Fabra, N. and Garca, A. (2015). Dynamic price competition with switching costs. Dynamic Games and Applications, 5(4):540-567. 
[17] Fang, H. and Silverman, D. (2004). Time-inconsistency and welfare program participation: Evidence from the nlsy. Cowles Foundation Discussion Papers 1465, Cowles Foundation for Research in Economics, Yale University.

[18] Fang, H. and Wang, Y. (2015). Estimating dynamic discrete choice models with hyperbolic discounting, with an application to mammography decisions. International Economic Review, 56:565-596.

[19] Farrell, J. and Klemperer, P. (2007). Coordination and lock-in: Competition with switching costs and network effects. volume 3, chapter 31, pages 1967-2072. Elsevier, 1 edition.

[20] Farrell, J. and Shapiro, C. (1988). Dynamic competition with switching costs. RAND Journal of Economics, 19(1):123-137.

[21] Gordon, B. (2009). A dynamic model of consumer replacement cycles in the pc processor industry. Marketing Science, 28(5):846-867.

[22] Gowrisankaran, G. and Rysman, M. (2012). Dynamics of consumer demand for new durable goods. Journal of Political Economy, 120(6):1173 - 1219.

[23] Heckman, J. (1981). Heterogeneity and state dependence. In Studies in Labor Markets, pages 91-140. National Bureau of Economic Research, Inc.

[24] Honoré, B. E. and Kyriazidou, E. (2000). Panel data discrete choice models with lagged dependent variables. Econometrica, 68(4):839-874.

[25] Honoré, B. E. and Lewbel, A. (2002). Semiparametric binary choice panel data models without strictly exogeneous regressors. Econometrica, 70(5):2053-2063. 
[26] Honoré, B. E. and Tamer, E. (2006). Bounds on parameters in panel dynamic discrete choice models. Econometrica, 74(3):611-629.

[27] Horsky, D., Polykarpos, P., and Minjae, S. (2012). Panel data discrete choice models with lagged dependent variables.

[28] Jorge, P. A. (1995). Revisiting dynamic duopoly with consumer switching costs. Journal of Economic Theory, 67(2):520-530.

[29] Kavka, G. S. (1994). Picoeconomics: The strategic interaction of successive motivational states within the person, george ainslie. cambridge: Cambridge university press, 1992, xvi + 440 pages. Economics and Philosophy, 10(02):333-338.

[30] Klemperer, P. (1987). Markets with consumer switching costs. The Quarterly Journal of Economics, 102(2):375-394.

[31] Laibson, D., Repetto, A., and Tobacman, J. (2007). Estimating discount functions with consumption choices over the lifecycle. NBER Working Papers 13314, National Bureau of Economic Research, Inc.

[32] Loewenstein, G. and Jon, E. (1992). Choice Over Time. Russell Sage Foundation.

[33] Paserman, M. D. (2004). Job search and hyperbolic discounting: Structural estimation and policy evaluation. 2004 Meeting Papers 99, Society for Economic Dynamics.

[34] Paulson, K. (2011). Using conditioning covariates to identify the dynamic binary choice model. 
[35] Pearsy, J. (2016). Bargains followed by bargains: When switching costs make markets more competitive. Journal of Economics and Management Strategy, $25(4): 826-851$.

[36] Rhodes, A. (2014). Re-examining the effects of switching costs. Economic Theory, 57(1):161-194.

[37] Shcherbakov, O. (2016). Measuring consumer switching costs in the television industry. RAND Journal of Economics, 47(2):366-393.

[38] Shi, M., Chiang, J., and Rhee, B.-D. (2006). Price competition with reduced consumer switching costs: The case of "wireless number portability" in the cellular phone industry. Management Science, 52(1):27-38.

[39] Shy, O. (2002). A quick-and-easy method for estimating switching costs. International Journal of Industrial Organization, 20(1):71-87.

[40] Sudhir, K. and Yang, N. (2014). Exploiting the choice-consumption mismatch: A new approach to disentangle state dependence and heterogeneity. Cowles Foundation Discussion Papers 1941, Cowles Foundation for Research in Economics, Yale University.

[41] To, T. (1996). Multi-period competition with switching costs: An overlapping generations formulation. Journal of Industrial Economics, 44(1):81-87.

[42] Viard, V. (2007). Do switching costs make markets more or less competitive? the case of 800-number portability. RAND Journal of Economics, 38(1):146-163.

[43] Wooldridge, J. (2005). Simple solutions to the initial conditions problem in 
dynamic, nonlinear panel data models with unobserved heterogeneity. Journal of Applied Econometrics, 20(1):39-54. 